\title{
Finishing procedures in Orthodontics: dental dimensions and proportions (microesthetics)
}

\author{
Roberto Carlos Bodart Brandão11, Larissa Bustamente Capucho Brandão²
}

Objective: The objective of the present article is to describe procedures that can be performed to achieve excellence in orthodontic treatment finishing. The content is limited to microesthetics, which comprises the concept of ideal dental dimensions and proportions (white esthetics) and its correlation with the periodontium (pink esthetics). Standards of normality are described both in their real dimensions (dental height and width), and in those effectively perceived by the observer, the virtual dimensions. Methods: The best scientific evidence was sought in the literature to support the clinical procedures that must guide the professional to obtain maximum esthetic quality on their treatments. Therefore, it is necessary to investigate what the other specialties in Dentistry expect from Orthodontics and, specially, what they have to offer. Clinical cases will be used to illustrate the dental movement that might maximize treatment outcome and to confront the ideal standards with the current state of the art. Conclusion: Treatment quality is directly related to the amount of procedures implemented by the orthodontist, associated with concepts and resources from Periodontics and Dental Prosthesis. Microesthetics cannot be seen in isolation, but rather as the key to establish a pleasant smile (miniesthetics) in addition to a harmonious face (macroesthetics) and a human being with high self-esteem (hyper-esthetics).

Keywords: Orthodontics. Dentistry. Dental esthetics. Smile.

Objetivo: o objetivo do presente artigo é descrever procedimentos que podem ser realizados para alcançar a excelência na finalização do tratamento ortodôntico. Delimita-se o assunto à micro-estética, que abrange o conceito das dimensões e proporções dentárias ideais (estética branca) e sua correlação com o periodonto (estética vermelha). Padrões de normalidade são descritos tanto em suas dimensões reais (altura e largura dentária), como naquelas efetivamente percebidas pelo observador, as dimensões virtuais. Métodos: buscou-se na literatura a melhor evidência científica para embasar os procedimentos clínicos que devem nortear o profissional para obter a máxima qualidade estética nos tratamentos. E, para tanto, há necessidade de investigar o que as demais especialidades da Odontologia esperam da Ortodontia e, principalmente, o que têm a oferecer. Casos clínicos serão utilizados para ilustrar a movimentação dentária que pode maximizar o resultado final do tratamento, e para confrontar com os padrões ideais para o estado da arte atual. Conclusão: conclui-se que a qualidade do tratamento está diretamente relacionada à soma de procedimentos implementados pelo ortodontista, associados a conceitos e recursos da Periodontia e Prótese Dentária. A micro-estética não pode ser vista de forma isolada, mas sim como parte fundamental para se estabelecer um sorriso agradável (mini-estética), uma face harmoniosa (macro-estética) e um ser humano com autoestima elevada (hiper-estética).

Palavras-chave: Ortodontia. Odontologia. Estética dentária. Sorriso.

How to cite this article: Brandão RCB, Brandão LBC. Finishing procedures in Orthodontics: dental dimensions and proportions (microesthetics). Dental Press J Orthod. 2013 Sept-Oct;18(5):147-74.

${ }^{1}$ Adjunct professor of Orthodontics, Federal University of Espírito Santo (UFES).

${ }^{2}$ Specialist in Orthodontics, Fluminense Federal University (UFF).
Submitted: August 05, 2013 - Revised and accepted: August 30, 2013

» The authors report no commercial, proprietary or financial interest in the products or companies described in this article.

» Patients displayed in this article previously approved the use of their facial and intraoral photographs.

Contact address: Roberto Carlos Bodart Brandão

Av. Américo Buaiz, 501/1007 - Torre Norte - Enseada do Suá

CEP: 29.050-911 - Vitória/ES - Brazil

E-mail: consultorio@ortobrandao.com.br 


\section{INTRODUCTION}

The subject of orthodontic finishing is instigating and extensive. After all, it is all about achieving the objectives of orthodontic treatment, seeking excellence of results, justifying the patient's financial investment and, consequently, prior professional referral, so that new treatments can be initiated. Adequately finishing the cases means investing in professional longevity, remaining in our work place with approval of the society colleagues and patients, in an increasingly competitive market, as a private pension in its true meaning, which is: to prepare the future.

For being quite a large subject, orthodontic treatment finishing must be discussed in four different and, at the same time, complementary, topics:

1) Fundamental principles.

2) Esthetic orthodontic procedures.

3) Transdisciplinary approaches.

4) Occlusal adjustment.

We began to discuss orthodontic finishing in a reverse order when the article Occlusal adjust in Orthodontics: why, when and how was published. ${ }^{8}$ This reverse order was purposeful. If the orthodontist intends to perform a quick and stable treatment, he must begin backwards, i.e., establish the best molar intercuspation as soon as possible, then premolars, enabling the perfect canine occlusion. Thus, a stable and reproducible occlusion, with no premature contacts, is established first. This is the foundation for the success in orthodontic finishing; the esthetic procedures will only be complete and durable if there is stability in dental occlusion. ${ }^{8}$
We also had the opportunity to approach the fundamental principles that guide orthodontic finishing in an interview, ${ }^{9}$ in which it was asserted that finishing begins even before the appliance is placed, paradoxical as it may seem. Most often, we are concerned about the finishing phase during the last months of orthodontic treatment, specially when the rectangular arches are placed. When this occurs, there is a waste of time and opportunities that could shorten and optimize orthodontic finishing. A solid planning and an individualized appliance placement define a better finishing. And it is worth remembering that treatment onset is when there is greater patient collaboration. When this collaboration is demanded at the final moments of treatment, what we have is a tired and, often, unmotivated patient. ${ }^{9}$

An interesting division of esthetics in Orthodontics is that presented by Sarver and Ackerman, ${ }^{48}$ who divided it into three sections: 1) Microesthetics, which includes the dental aspect, considering the arrangement of teeth on the arches, their color, shape, dimensions and proportions; 2) Miniesthetics, which includes smile esthetics, how teeth are exposed and perceived in smile dynamics, specially its relation with the lips; 3) Macroesthetics, which refers to the face, its harmony and proportions, and the esthetic impact of the several structures in its composition (Fig 1).

In this article, the Microesthetics approach, specially the dental dimensions and proportions, with its variations, will be discussed within the topic Esthetic orthodontic procedures.
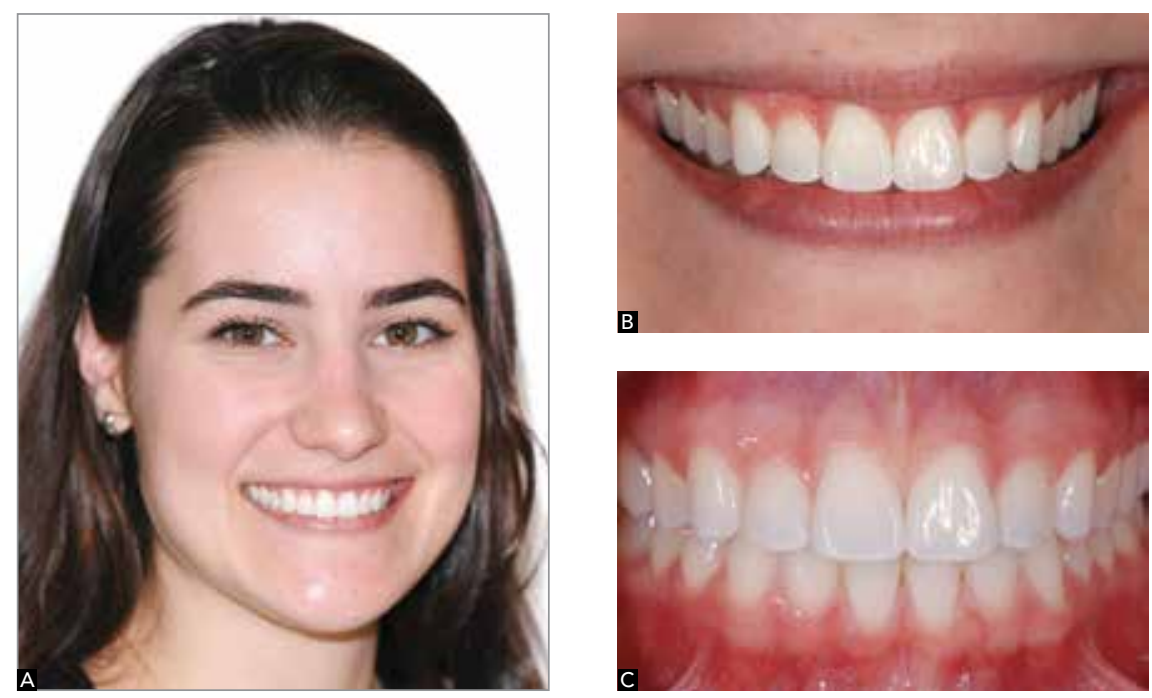

Figure 1 - Esthetical approaches according to Sarver and Ackerman ${ }^{48}$ : A) Macroesthetics, seeks the harmony of facial structures; B) Miniesthetics, evaluated by the oral structures that comprise the smile; C) Microesthetics, related to the teeth and to the periodontium. 


\section{ESTHETIC IMPACT OF DENTAL DIMENSIONS AND PROPORTIONS}

The fact that the evaluation of facial beauty is essentially subjective cannot be forgotten. The artist Albrecht Dürer, ${ }^{16}$ from the XVI century, wrote: " I don't know what beauty is, but I do know it affects many things in life", and considered that, although the concept of facial beauty is immersed in subjectivity, the evaluation of facial proportions could be objectively performed. The discussion is about how ideal patterns can be defined, within a theme that experiences important changes with the evolution of society. ${ }^{44}$

In a recent study, Orce-Romero et al..$^{45}$ investigated the common characteristics which influenced esthetical perception in different populations around the world. This study was based on the analysis of the smile of 500 celebrities exposed on Time magazine. They found that upper lip vertical height, smile width, upper central incisors exposure, dental symmetry and intra-dental proportions are the most influential factors in defining a smile as pleasant, corroborating the findings of other authors who found an evolution on the esthetical criteria of professionals and laypeople. ${ }^{3,25,25,52}$ Four of these factors are characteristics related to microesthetics and, if well managed by the orthodontist and his team of colleagues of related specialties, are determinant to achieve the esthetical excellence of the smile.

It is important to note that there is a wide range of combinations of smile characteristics that make it more or less pleasant, specially when the entire face of the patient is included in the observation. Kokich Jr, Kiyak and Shapiro ${ }^{35}$ observed that people, when seeing a smiling face, look first and for a longer period of time to other areas of the face before they look at the teeth. For this reason, microesthetics must be considered within a context: other variables related to the smile (miniesthetics) and to the face (macroesthetics) must be in harmony with the proportions and dimensions in the dental arches.

\section{WIDTH AND HEIGHT OF CROWNS}

There is a variation on dental dimensions that can be considered as normal or desirable, specially when considering that there are individuals with different facial patterns. Some works show that the dimensions of anterior teeth can be defined within a limited range. The height of the central incisor varies from 10.4 to $11.2 \mathrm{~mm}$ while its width varies from 8.73 to $9.3 \mathrm{~mm}$, and, usually, these references are used in prosthetic reconstructions, when no other parameters are available. ${ }^{37,54,55}$

The most important is the correlation of these dimensions, i.e., the dental proportions. ${ }^{4,20,50}$ Two proportions must be considered: the relation between height and width of each tooth, and the relation of height and width among the teeth. In these cases, we will always be referring to the real dimension of the teeth, i.e., the clinical crown dimensions of anterior teeth.

A classic study that investigated dental proportions was that by Gillen et $\mathrm{a}^{20}$ who found the following proportions of width among the upper anterior teeth: a) lateral incisors have $78 \%$ of the width of the central incisor (lateral incisor $=$ central incisor $\mathrm{x} 0.78)$; b) lateral incisor has $87 \%$ of the width of the canine (lateral incisor $=$ canine $\mathrm{x} 0.87)$; c) canine has $90 \%$ of the width of the central incisor (canine = central incisor x 0.90), as shown in Figure 2.

The studies by Sterrett et al. ${ }^{58}$ demonstrated that the relation between width and height of central and lateral incisors and canines is practically the same in both genders. Females tend to have slightly wider teeth in comparison to males, being: central incisors $86 \%$ and $85 \%$, lateral incisors $79 \%$ and $76 \%$, and canines $81 \%$ and $76 \%$, respectively. The most recent research available found the proportion between height and width of upper anterior teeth ranging from 75 to $80 \%$ in central incisors, from 66 to $70 \%$ in lateral incisors, and from 80 to $85 \%$ in canines, without statistical difference between men and women. ${ }^{45}$

Most authors define the height/width ratio of 0.80 for the upper central incisor (which represents the key tooth to esthetical composition of the smile) as a standard to be used in Prosthesis, Periodontics and Orthodontics. ${ }^{50,55,58}$ Therefore, on establishing ideal widths, based on intact teeth, it is suggested to use the proportion of $80 \pm 5 \%$

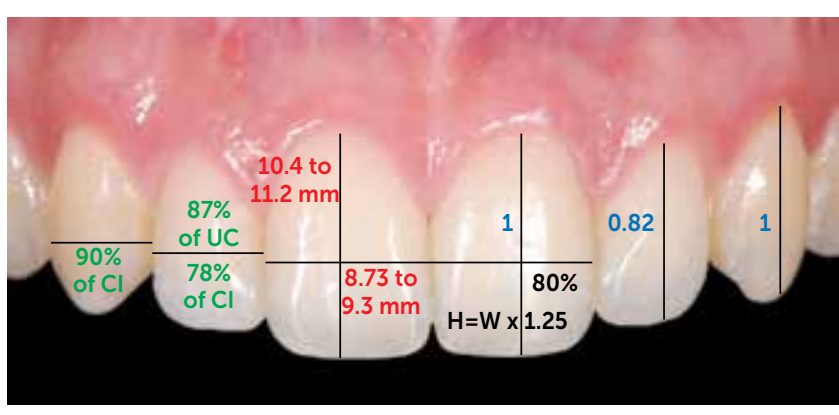

Figure 2 - Real proportions and dimensions of teeth with four approaches variations on the dimensions of height and width of the central incisor (red). height/width proportion of the central incisor (black), relations of width between anterior teeth (green) and relations of height of anterior teeth (blue). 
to define the ideal height, relating it to the facial pattern and to the individual's natural dental proportions (Fig 2).

The relation of proportion between the crown heights of anterior teeth proposed by Gillen et al. ${ }^{20}$ is widely used. It suggests that the height of the clinical crown of the upper lateral incisor must be $82 \%$ of the height of the crowns of the central incisor and canine. Therefore, canines and upper central incisors would have the same anatomical crown height. (Fig 2). This study was used to justify the bonding of orthodontic brackets at the same height for canines and upper central incisors, during placement of the orthodontic appliance.

In the decision making process, these proportions must be considered in two clinical situations. The first one is when interproximal wear is used to obtain space in the dental arch, or to close black spaces when the contact point is brought closer to the alveolar bone crest, which shall be discussed in a specific topic later on. The second situation in which the height $\mathrm{x}$ width relation is essential occurs when the patient has loss of dental volume, compromising the height of the crown, when there is incisal wear by attrition or abrasion, or compromising the width of the crown due to cavities or unsatisfactory restorations. The recovery of these proportions must be defined during treatment planning, and it would be a priority for the definition of transverse and vertical corrections of the dental arches. ${ }^{30,57}$ When loss of dimensions of the upper anterior teeth is detected, the first treatment step must be to provide spaces for these dimensions to be restored within the ideal proportionality, using extractions, distalizations or maxillary expansions, even when surgical assistance is necessary (Fig 3).

Another practical way to use dental proportions to establish the width of anterior teeth is by fixed measures, based on averages of tooth size. ${ }^{14}$ In this case, database of tooth sizes of different populations are used, which generates formulas for the dental widths to relate to each other, specially for anterior teeth. Figure 4 shows a proposal of a mathematical formula used to define the size of a tooth based on the size of other teeth. In this case, the letter Y represents the width of the upper central incisor and the letter X, the width of the lower central incisor. ${ }^{14,15}$ The width of the upper lateral incisor would be the width of the upper central incisor minus $2 \mathrm{~mm}$, and the width of the upper canine would be the width of the central minus $1 \mathrm{~mm}$. Based on the width of the lower central incisor, the width of the upper central incisor would be defined by adding $3 \mathrm{~mm}$, while the width of the lower central incisor would be defined by adding $0.5 \mathrm{~mm}$, and the width of the lower canine by adding $1 \mathrm{~mm}$.

Contrary to golden proportions and based on measures of dental dimensions and of harmonious proportions derived from observations on the population, as those previously described, $\mathrm{Chu}^{14,15}$ developed an instrument to measure proportionality. This proportionality gauge (commercialized by Hu-Friedy ${ }^{\circledR}$ ) does not need mathematical calculations and uses a formula that was predetermined by its creator, for dental proportions that are visually available in a color scale that must be considered by the professional. In other words, for each tooth width marked by the colors on the horizontal rod of the measurer, it would be necessary that the height of the crown were equivalent to the same color available on the vertical rod, this would define the best proportion (Fig 5).

\section{CROWN VIRTUAL WIDTHS}

Real width and height are data based on direct measurements carried out on the teeth (anthropometric measures), i.e., their absolute dimensions. It is recommended to consider the virtual dimensions which are, effectively, what is perceived by people - the esthetics that really matters.

The perception of dental dimension different from reality is a physical, better yet, optical phenomenon. When we take a shower with a green soap, we evidently do not become green, because there is no pigment in the soap, but rather an optical phenomenon, due to the arrangement of the crystals of the soap that reflect only part of the light spectrum, where the green color is. We only see what is reflected to our retina; the part of light that focuses an object and is deflected in another direction, or absorbed, escapes our visual perception. Therefore, the flat surfaces are completely perceived by the reflection of light that focuses in $90^{\circ}$ on them - it is what we effectively clearly see, the virtual dimensions of the teeth. The shades represent the curved surfaces where the light is deviated in another direction, because it is deflected. ${ }^{40}$

The dimension of the virtual width of the teeth follows its position, the shape of the dental arch and the anatomy of each tooth. The central incisors, for being closer to the observer, at the front of the dental arch, are privileged by the parallax effect, attracting the perception of the human eye. ${ }^{10}$ Starting with the concept of central incisor predominance, the perception of the other teeth in the anterior region begins to follow the golden proportion. 

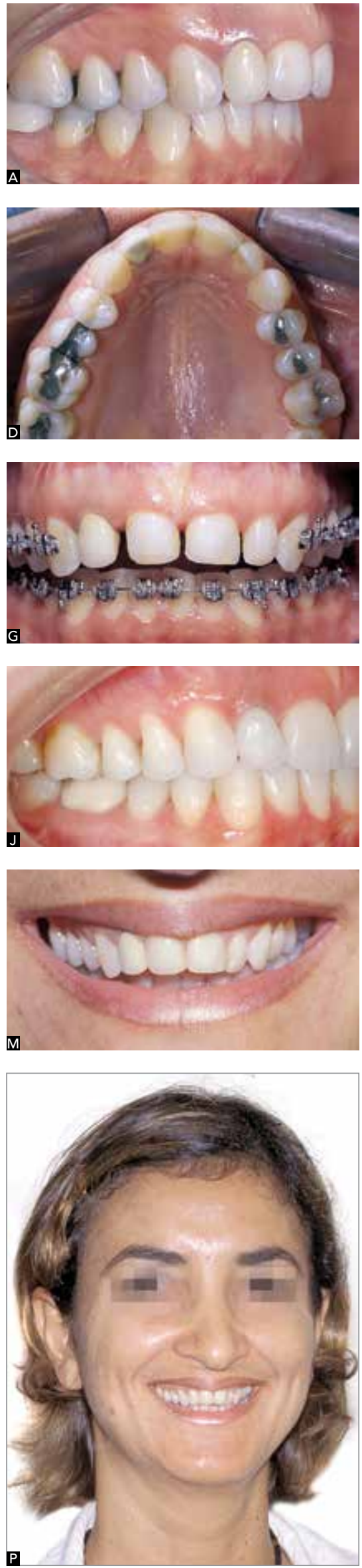
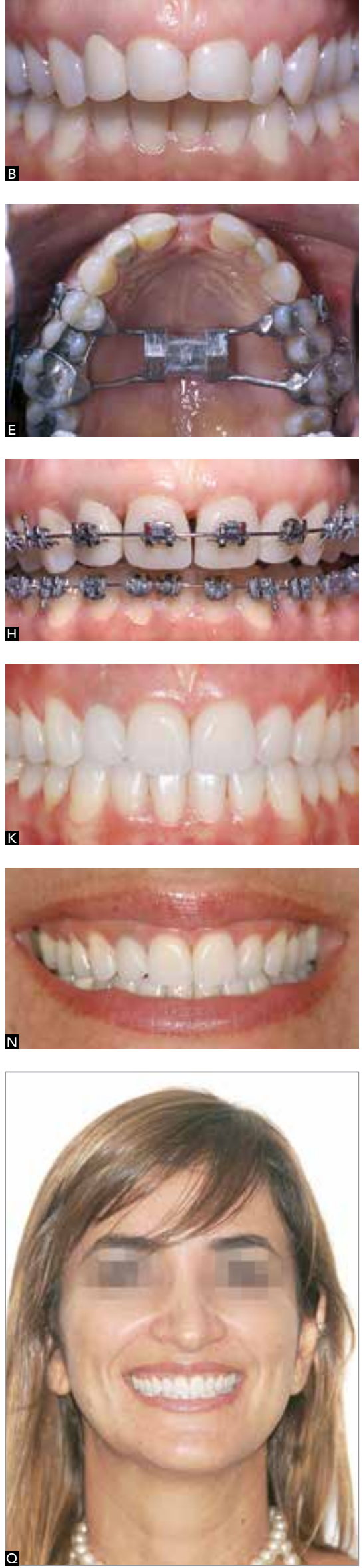
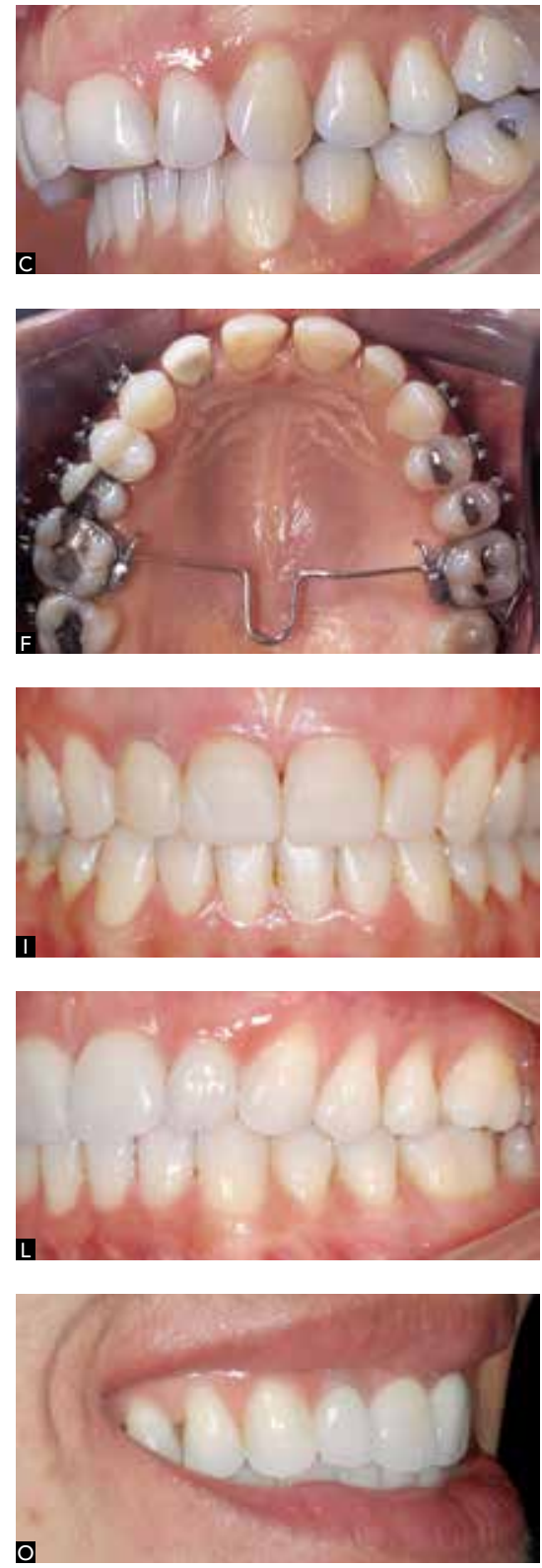

Figure 3 - Orthodontic-surgical treatment of Class II division 1 malocclusion, with two surgical times. A, B, C, D) Transverse maxillary atresia, with narrow and disproportionate anterior teeth E) Surgically assisted maxillary expansion with Hyrax, maintained for 8 months. F) Transpalatal bar with dental anchorage. G) Definition of spaces and bracket removal referring to Restorative Dentistry. H) Rebonding of brackets after restorations, under completion. I) Immediate result after Orthodontics. J, K, L) Results of occlusion after prosthodontics had been finished. $\mathrm{M}, \mathrm{N})$ Comparison of the smile, before and after. O) Lateral view of the final smile. P, Q) Repercussion on facial esthetics, before and after. 


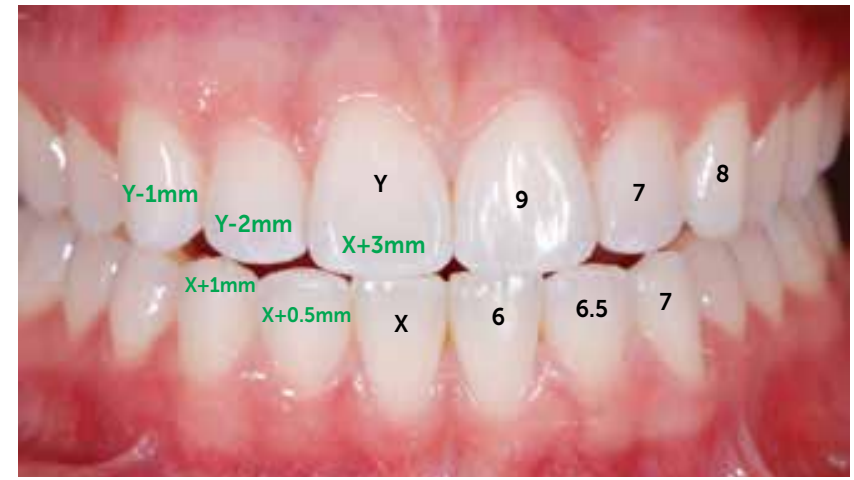

Figure 4 - Formulas to achieve the best relation between the widths of anterior teeth, emphasized by Chu, ${ }^{14,15}$ enabling definition of the width of a tooth based on the dimension of another. In the left hemiarch, example of application of the formulas of correlation between the dental widths.
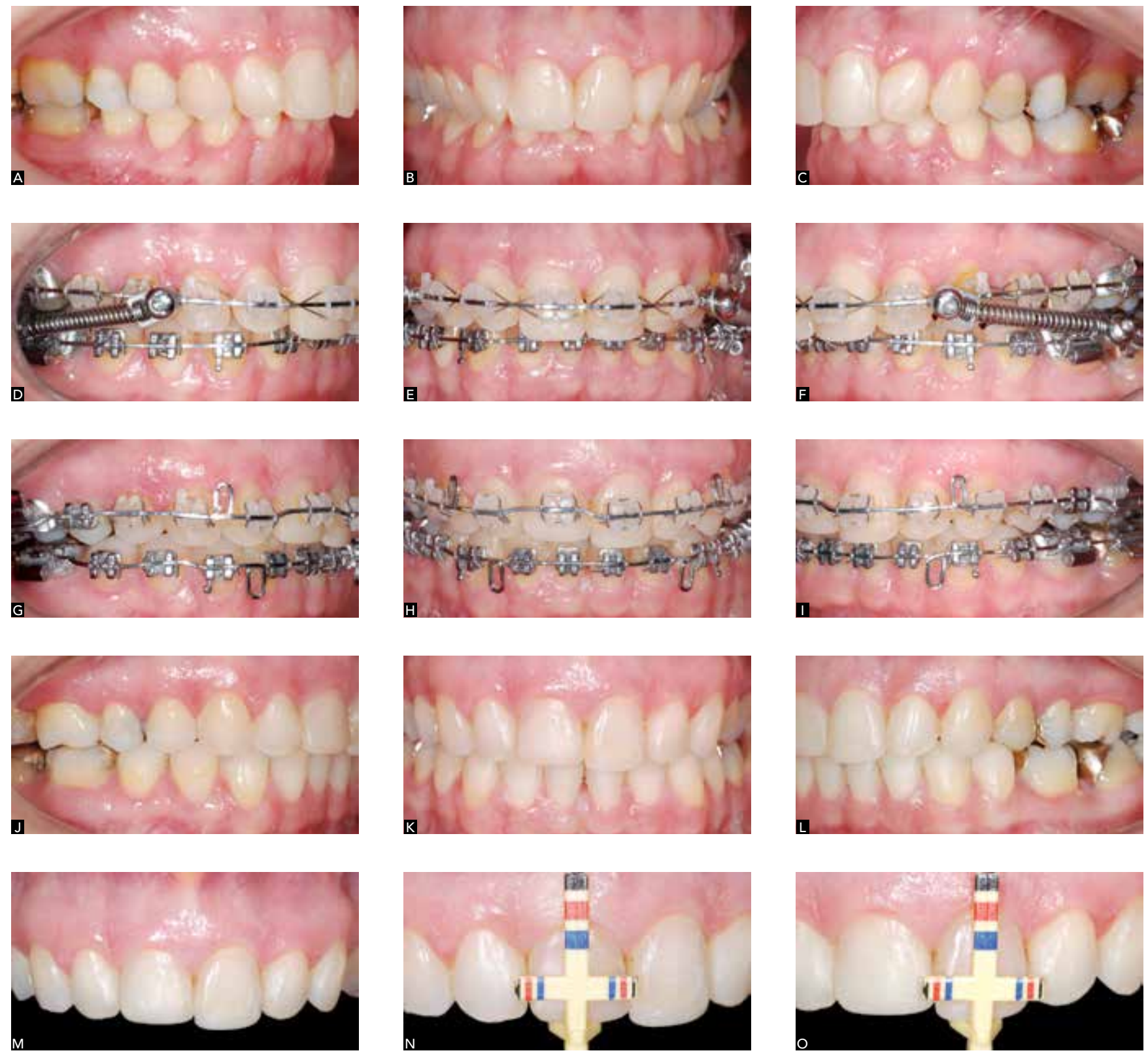

Figure 5 - Class II division 1 patient, right subdivision with excessive overbite. A, B, C) Initial case, upper arch with atresia and asymmetric extrusion of anterior teeth. D, E, F) Dynaflex ${ }^{\circledR}$ appliance, for action similar to the Class II intermaxillary rubber bands. G, H, I) Correction of gingival contour, intruding the right upper central incisor. J, K, L) Immediate result after Orthodontics, central incisors with asymmetric dimensions. M, N, O) Verification of height and width proportions with Chu's gauge, ${ }^{15}$ showing that the teeth should be dimensioned by the red marking, as the left central incisor. 

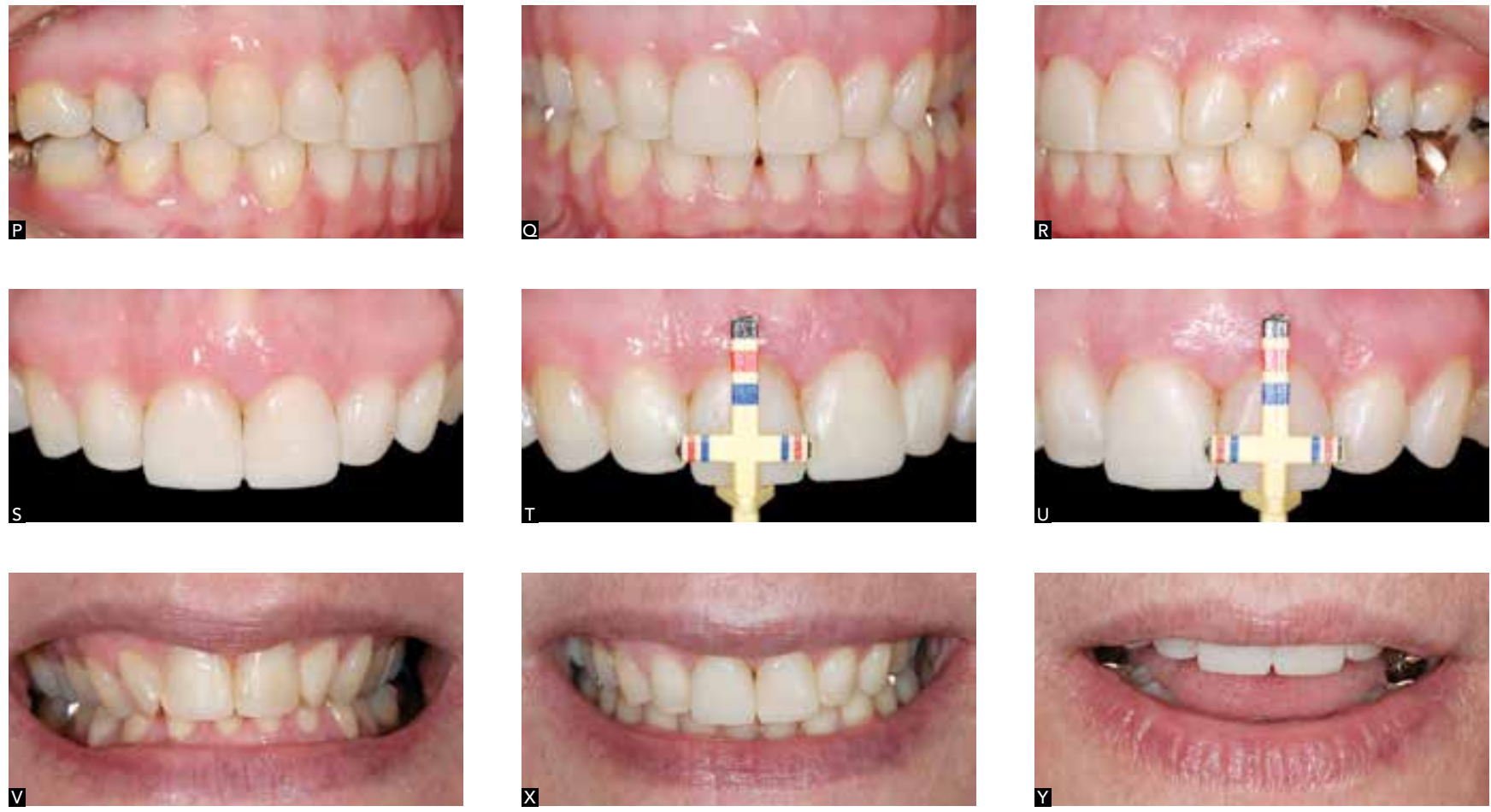

Figure $\mathbf{5}$ (continuation) - P, Q, R) Restorations in provisional resin, serving as mock-up for the patient to give his opinion and also guide the prosthodontist. S, T, U) Verification of the symmetry and proportions achieved. V) Smile before treatment, wide buccal corridor. X, Y) Smile and speech after Orthodontics and provisional restorations.

Also known as divine proportion, the golden proportion rises from an algebraic constant denoted by the greek letter $\phi$ (phi), with approximate value of 1.618 , and it is used in arts, since Antiquity, by sculptors and painters. It defines the size proportion between structures or parts, directly related to harmony. This proportion was verified in human beings, related to the size of phalanges and to growth, and introduced in Dentistry by Lombardi, ${ }^{36}$ when it began to be used as a parameter for the evaluation of smile amplitude measure and of the visible portion of the teeth. The distal reduction of the virtual width of the teeth must be similar to this constant. By this parameter, the lateral incisors must appear proportionally smaller (62\%) in relation to the central incisors. Similarly, the proportion of canine appearance in relation to the lateral incisors must be $62 \%$ smaller and coincident with the appearance proportion of the premolar, and so on (Fig 6).

The upper central incisor and the canine have approximate real dimensions, but the virtual width of the canine, due to its convex anatomy and position on the dental arch curvature, represents only 33\% of the virtual width of the central incisor. This tooth is privileged by its wide flat surface, reflecting most of the light that focuses on its clinical crown. A tool that is widely used by Dental Prosthesis is the generation of optical illusion, for example, when the central and lateral incisors have approximate sizes: the professional builds different anatomical contours on the restoration or on the porcelain crown, totally flat on the central incisor, increasing its virtual width, and with marked curvature on the distal face of the lateral incisor, hiding its real dimension. . $^{2,19,37}$

The possibility of working with optics, modifying the virtual width of the teeth, can be verified in two situations. The first one is related to the torque effects on the posterior teeth, and influences on the buccal

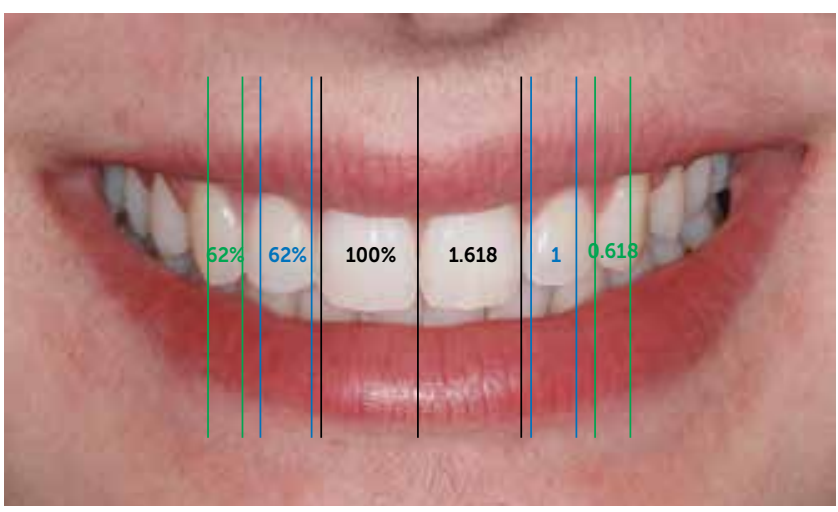

Figure 6 - Virtual width of the teeth, taking the golden proportion as parameter There is a reduction in the perception of the size of teeth from the central incisors on due to the smaller flat area available to reflect light. The conformation of the arches, dental alignment and shape of the teeth define the amount of flat surface on which the light will focus and, thus, the beauty and naturality of the smile. 
corridor and on the smile amplitude. In expanded arches, due to the buccal torque of the crowns of posterior teeth, the teeth seem to be larger or in greater amount in the oral cavity. ${ }^{8}$ On the other hand, in contracted arches, due to the excessive lingual torque of the crowns of posterior teeth, the teeth seem to be smaller, with little expression in the smile, and wide and dark buccal corridors. In these cases, the contraction or expansion of the dental arches, at the expense of coronary movement, and the definition of the correct implantation of teeth on their bone base may significantly change the esthetical perception of size and number of teeth in the smile. It is clear that the best buccal corridor and the best amplitude of the smile are established with adequate torques on canines and posterior teeth (Fig 7).9,47

The other way to work the virtual width to achieve the best esthetics is related to correct dental alignment, specially when the dental arch shape is respected, setting the teeth with well positioned contact points in the buccolingual direction, without rotations. Otherwise, mesially rotated teeth tend to expose more the clinical crown to the light, making the real width larger. This might generate the illusion of a lateral incisor or canine with dimensions that are larger than or equivalent to the central incisor. A distal rotation hides the buccal surface, creating the appearance of microdontia.
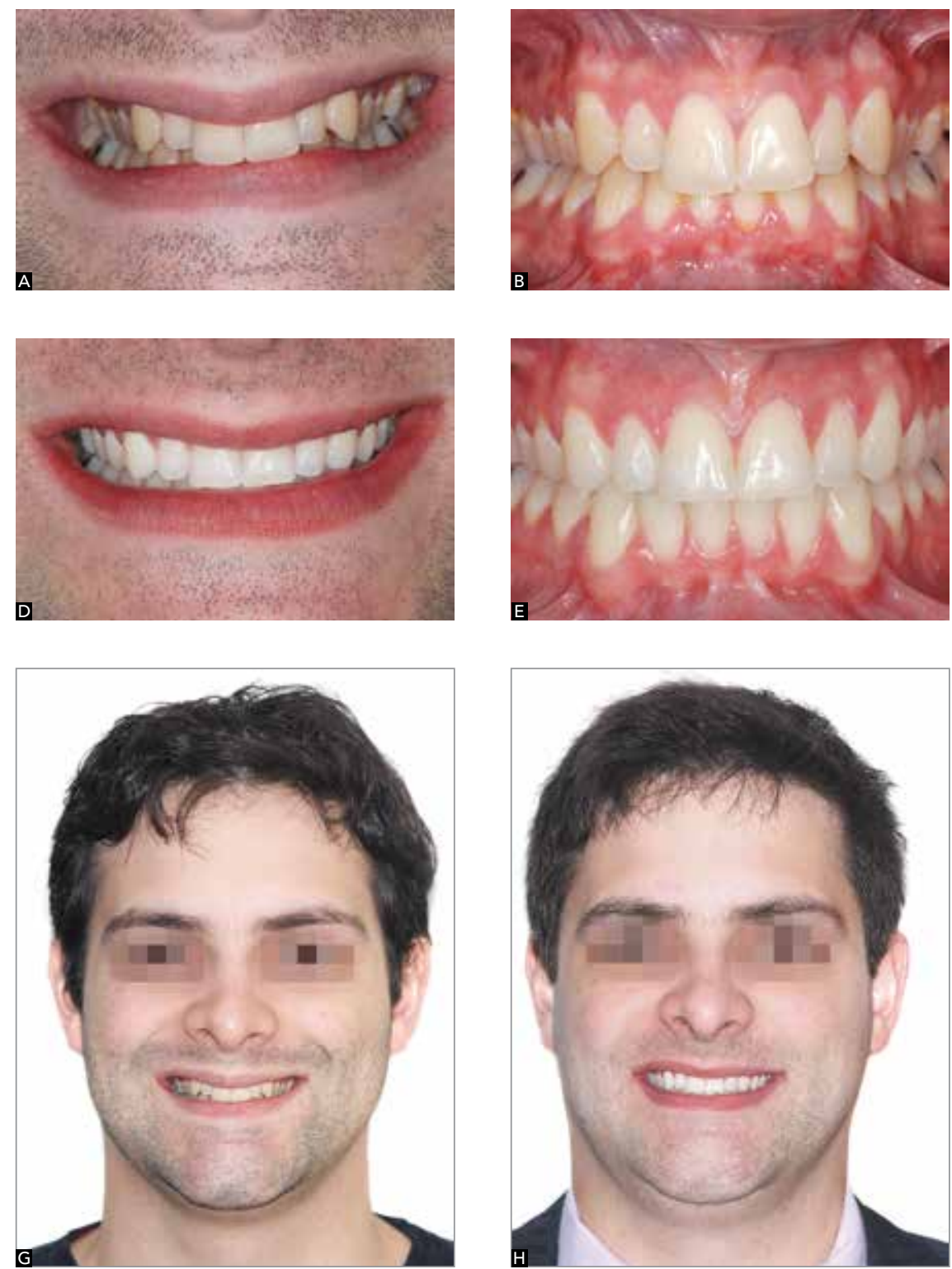
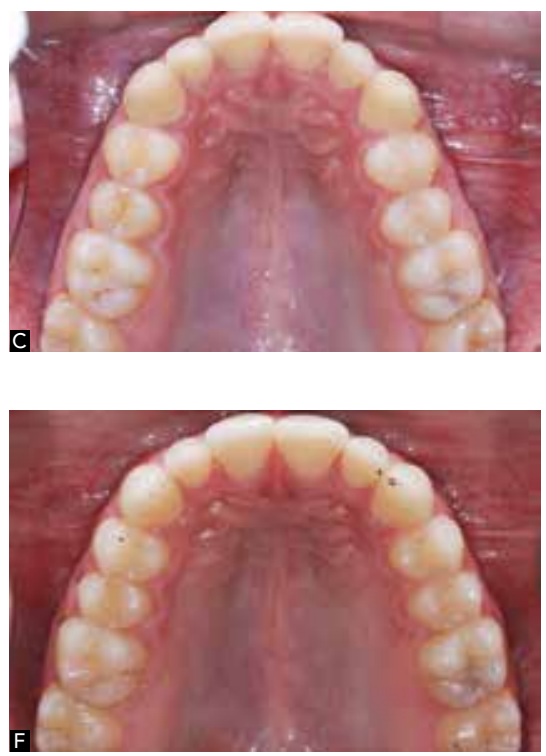

Figure 7 - Patient whose complaint was related to teeth with disproportionate sizes. A, B, C) Very wide buccal corridor due to transverse atresia of the dental arches, hiding the posterior teeth in the shade of the canines. D, E, F) Placement of teeth in the bone bases, with dentoalveolar expansion, resulting in normal buccal corridor and pleasant smile. G, H) Smiling face before and after Orthodontics and teeth bleaching. Note the aspect of larger teeth, now with proportional dimensions, with no need for restorations. 
In this case, when the professional is concerned about placing the teeth well implanted into the bone base, there is anatomical integrity and the contact points are correctly established, which automatically generates the best optical response to light propagation. The orthodontist must achieve the expression of what naturally occurs when a normal occlusion is exposed in different situations of speech and smile. ${ }^{1,10,50}$ Figure 8 shows the behavior of light, considering the normality in dental alignment and in the arch shape, with maximum reflection of light in the anterior areas and a progressive increase of light deflection in the distal direction, which does not return to the observer's retina.

However, there are situations in which the professional might have to intervene in a different manner, specially when there are limitations for teeth positioning in the bone base, which is common in cases of transverse skeletal asymmetry. We oftentimes face asymmetric mandibular growth, which generates mandibular laterognathism, displacing the entire lower bone base to one side, a situation defined as prevalent in the population, according to Duthie et al. ${ }^{17}$ Many times, this happens due to late expression of growth, a nightmare in orthodontic clinic that can lead cases that were under clinical control to orthognathic surgery. In less dramatic cases, asymmetry may be disguised, which compromises the ideal position of the teeth in the bone base. In these cases, the teeth in the upper arch have their crowns buccally tipped, following the mandibular laterognathism. At the same time, the teeth on the same side of the mandible are lingually tipped. ${ }^{42}$ Specially in the upper arch, this buccal tipping is biologically recommended because of its thinner gingival tissue, specially in the upper canines and first premolars regions. ${ }^{43}$ In the case of misaligned bone bases, should the ideal torques be established, the canine root would be moved against the thin buccal bone plate, significantly reducing the thickness of the periodontium and increasing the risk of periodontal recession. Even if not immediate, periodontal recession may occur in the long-term due to canine positioning and volume, since it is the tooth that is most susceptible to trauma caused by toothbrushing. ${ }^{61}$

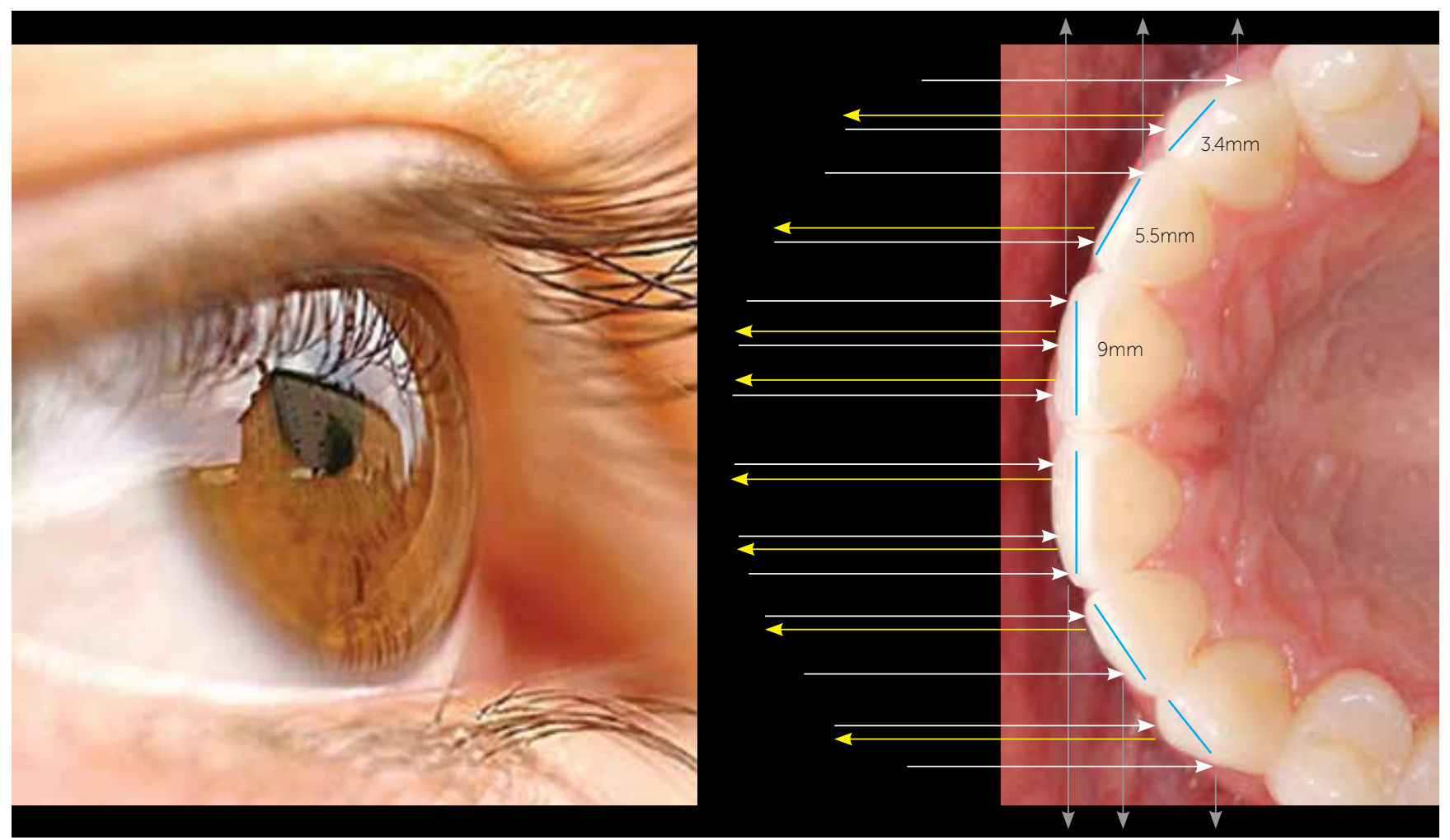

Figure 8 - Virtual width. Behavior of light focusing on anterior teeth (white arrows). Phenomenon that defines the virtual width, in which the central incisors, with larger flat area (blue line), reflect nearly all the light (yellow arrows); while on the canine, with a little more than $1 / 3$ of the area that generates reflection of light, the deflection of light (gray arrows) predominates, which is explained by its position in the arch and convex anatomy 
According to Karring et $\mathrm{a}^{24}$ even in teeth not orthodontically moved, a periodontuim with no alveolar bone is often found, by dehiscence or fenestration; therefore, a solid periodontal evaluation is recommended before inserting thick rectangular wires. ${ }^{8,9}$

In order to reverse the esthetical impairment of a canine buccal crown torque, procedures that lead to optical illusion can be used, an esthetical disguise that is essential in cases of orthodontically compensated skeletal asymmetry (Fig 9). The base of the procedure is an ameloplasty that hides the distal part of the buccal surface of the buccally tipped canine. It is necessary to divide the buccal surface into two and wear out the distal part of the crown with finishing burs, accentuating the curvature in the crown anatomy until there is no reflection of light and it is in the shade, due to light deflection. After one half of the buccal
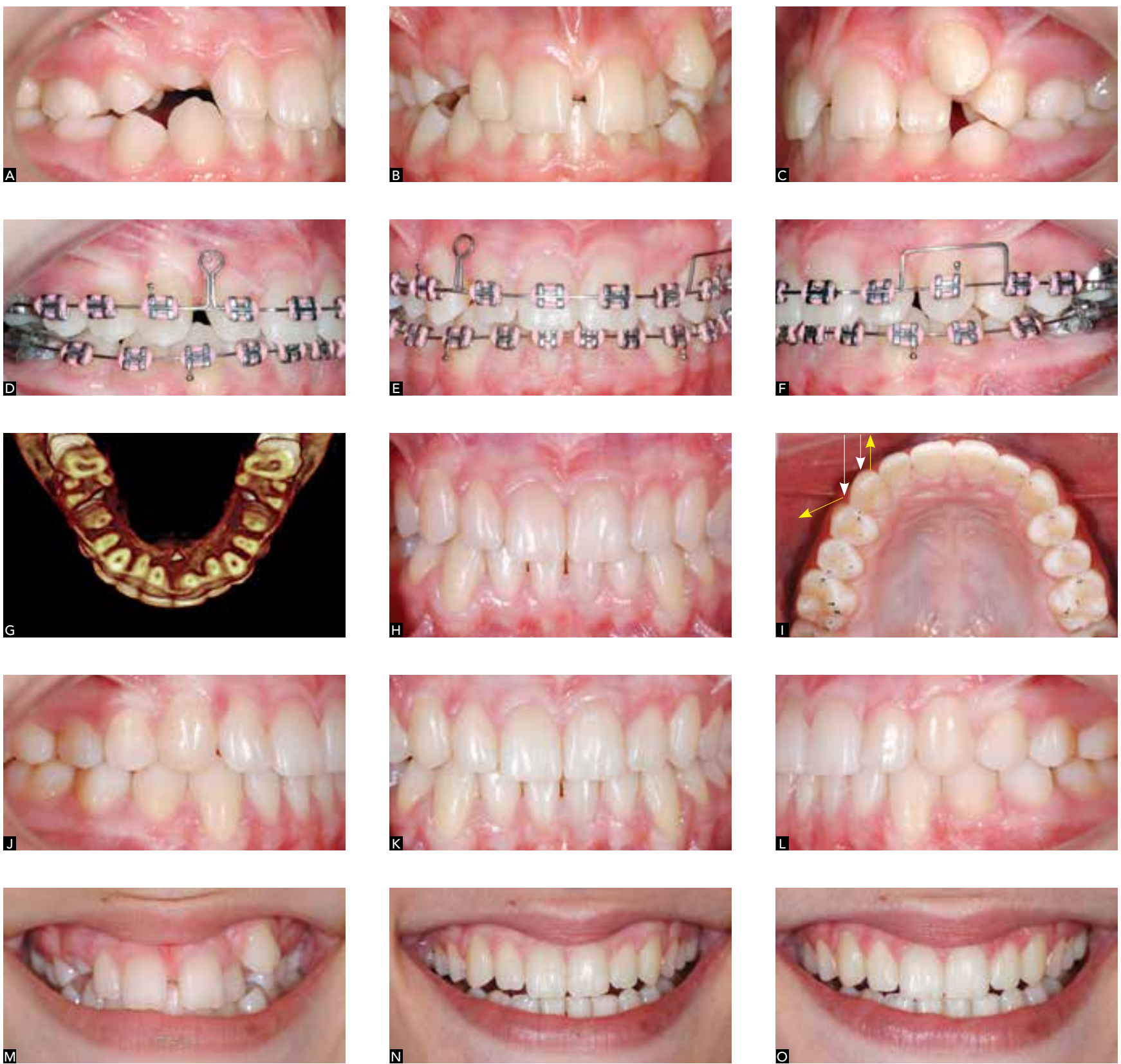

Figure 9 - Patient, whose mother had mandibular asymmetry, underwent orthodontic-surgical treatment. A, B, C) Transverse maxillary atresia, with crowding and deviation of the midlines. D, E, F) Orthodontic treatment with arch of midline correction. G) Tomographic slice, top view of the maxilla, showing minimum thickness of alveolar bone in the canine buccal surface. H) Final photograph of the treatment, with evident inappropriate torque of tooth \#13, because buccal root movement was avoided due to periodontal risk. I) Ameloplasty on the distal half of the buccal surface of tooth \#13, reducing reflection of light (arrows), with effect of optical illusion, reducing the virtual width of this tooth. J, K, L) Final result of the occlusion. Smile before (M) and after treatment (N), torque of tooth \#13 was compensated. O) Smile after ameloplasty, virtually reducing tooth \#13 due to the smaller flat area exposed to light. 

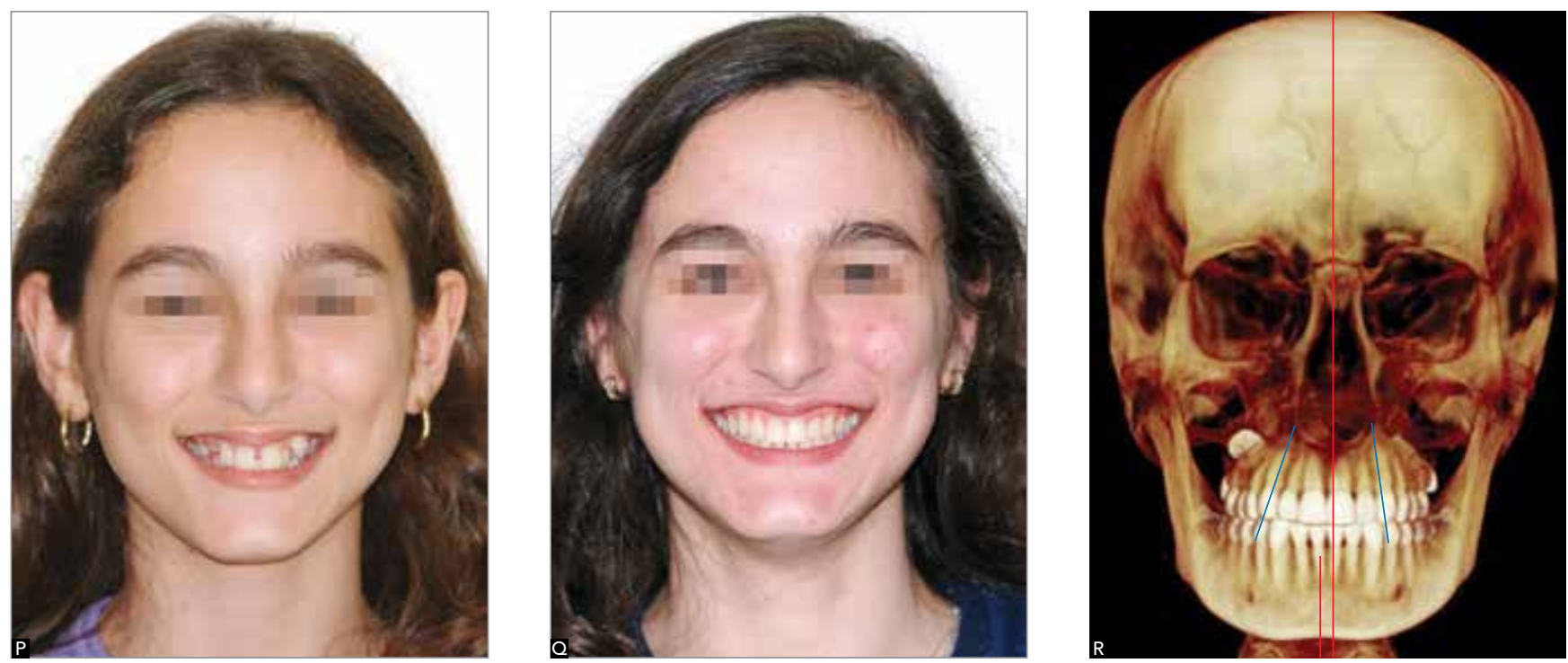

Figure 9 (continuation) - Smile before (P) and after treatment (Q). R) Tomography obtained after treatment, showing the different torques on the upper canines, adequate to mandibular asymmetry.

surface of the canine has been "hidden", polishing with abrasive rubbers is performed and the use of sodium fluoride at $0.05 \%$ is prescribed for daily mouthwash.

\section{VIRTUAL HEIGHT OF CROWNS}

A reasoning similar to the optical explanation that defines the virtual width must be applied to the virtual height. In other words, there is an alteration on the amount of light reflected over the patient's clinical crown, a difference between real and virtual height. (Fig 10) This difference is directly related to the torque of the upper anterior teeth that deflect most of the light emitted on the clinical crowns: upwards, when torque is excessive; or downwards, when the crowns are retroclined. A similar effect occurs when the occlusal plane is too posteriorly inclined or too flat. ${ }^{53}$

The correction or control of anterior teeth torques defines the success in obtaining the best expression of the dimensions of the dental crowns, when exposed to light. ${ }^{47}$ Special attention must be given to torque control in cases in which there will be great retraction of anterior teeth, quite common in Class II division 1 patients, treated with upper first premolars extractions. Third order bend should be emphasized in the retraction arches or high torque brackets should be used at this stage.

Cephalometry is traditionally used for evaluation of torques in anterior teeth and, based on these data and on the treatment strategy, the orthodontic mechanics is defined, with greater or minor concerns over root control. As long as it is correctly obtained, the procedure of reading the light generated by the flash of the camera used for intraoral photograph is also employed. According to Masioli, ${ }^{38}$ the correct position for frontal intraoral photograph is with the center of the photograph coinciding with the intersection of the mid sagittal plane with the occlusal plane. In order to obtain natural head position, the camera lens must be directed perpendicularly to the coronal plane of the patient's head and parallel to the Camper's plane whereas the focus must be established between the upper central incisor and the canine (Fig 11).

When the incisors present ideal torques, in natural head position, the flash is reflected to the maximum in the middle of the clinical crowns of these teeth. The flash cervically displaced indicates that the incisors have insufficient lingual root torque (Fig 12B), while the light displaced to the incisal edge indicates upper incisors with excessive lingual root torque. This perception and the routine of photographing the evolution of treatment, not only enhances professional learning, but avoids excessive exposure of the patient to radiation.

Considering this information, patients with Class II division 2 or Angle Class I malocclusion, who have labial musculature with accentuated tonus and usually present excessive overbite and retroclination of upper incisors, are specially esthetically benefited when the anterior teeth 


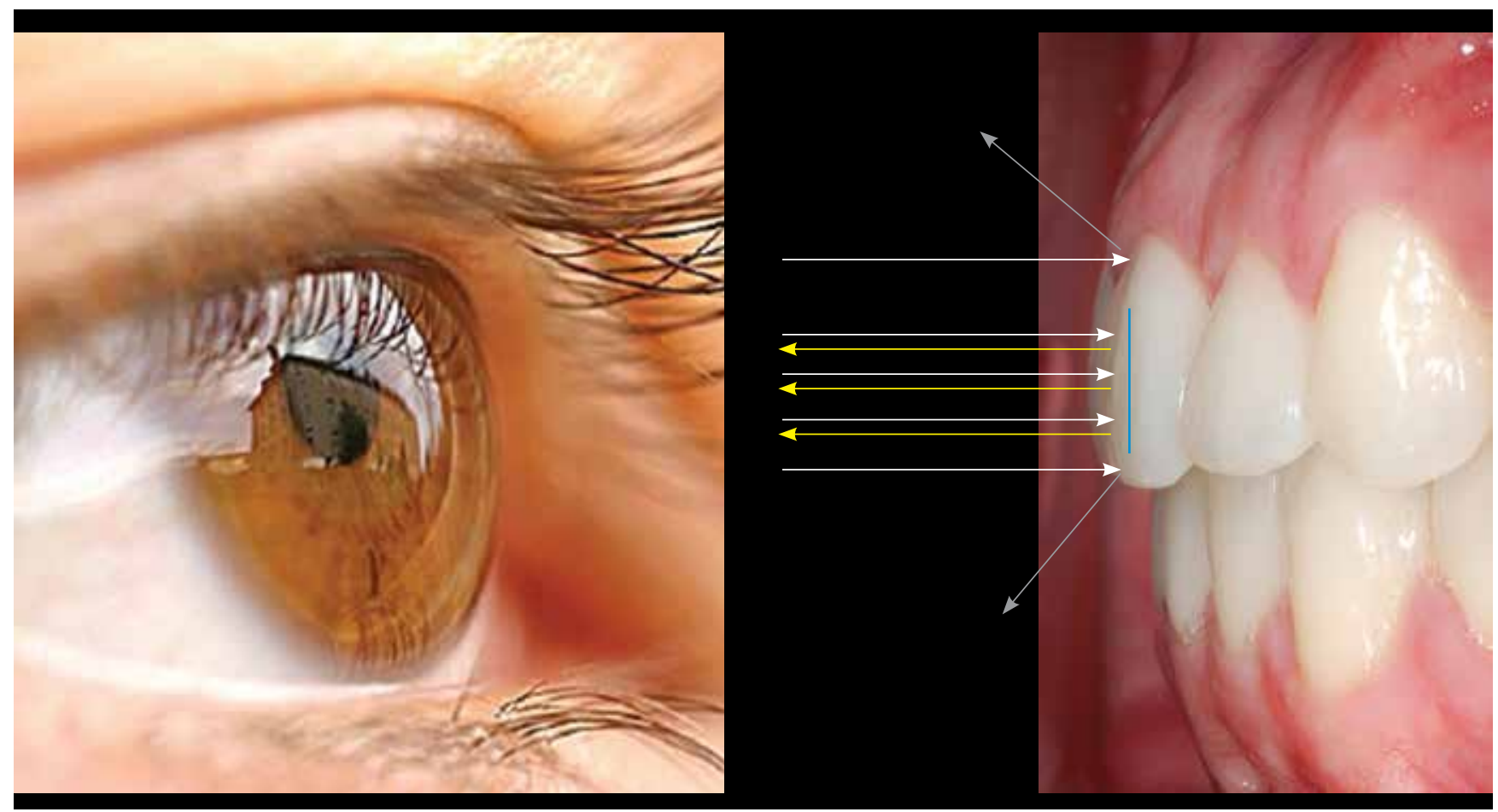

Figure 10 - Virtual height. Behavior of light focusing on anterior teeth (white arrows). Phenomenon that defines the virtual height: if the tooth is with adequate torque, the flat surface of the tooth is large and is at the center of the crown (blue line), reflecting most of the light that focuses (white and yellow arrows). The cervical and the incisal borders generate deflection of light (gray arrows).

are positioned at their correct tipping in the bone base. This finding can be seen in Figure 12 which reveals that during correction of malocclusion, significant improvements occurred in the torques of anterior teeth, which was easily perceived by the area in the crown where there was flash light reflected, migrating from the cervical to the middle of the upper incisor crowns.

Moreover, dental double protrusions are examples of how the appearance of the size of anterior teeth can be improved by orthodontic treatment. Figure 13 presents an adult female patient with excessive incisor proclination, but with a pleasant facial profile. In order to avoid extractions and, specially, the loss of lip support, it was decided to correct the excessive anterior teeth torques with the minimum retraction of these teeth. The patient was treated with controlled tipping, with movements lingually performed in the incisor crowns and maintenance of root apices in position. This way, all necessary spaces were obtained with generous interproximal wear on the posterior teeth, associated with temporary anchorage devices. Thus, an increase in the virtual height of these teeth was obtained with expanded reflection of light, since their buccal surfaces were buccally inclined, exposing a larger flat area of the clinical crowns to light, which is more pleasant and natural. ${ }^{12,26,36}$

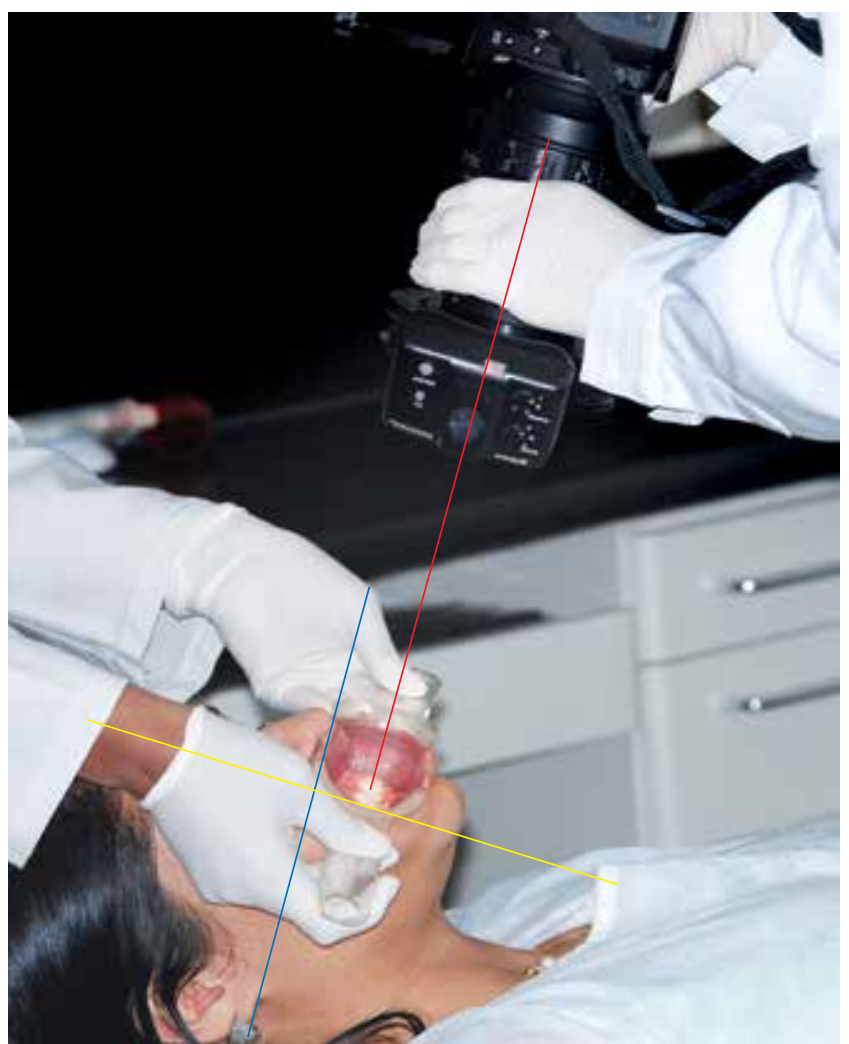

Figure 11 - Frontal intraoral photograph. Note that the lens are directed towards the central incisors, perpendicular to the coronal plane of the patient's head. The lens must also be parallel to Camper's plane (tragus - wing of the nose), defined as the natural postural plane, different from the occlusal plane, which may vary with treatment and may influence the expression of dental torques. 

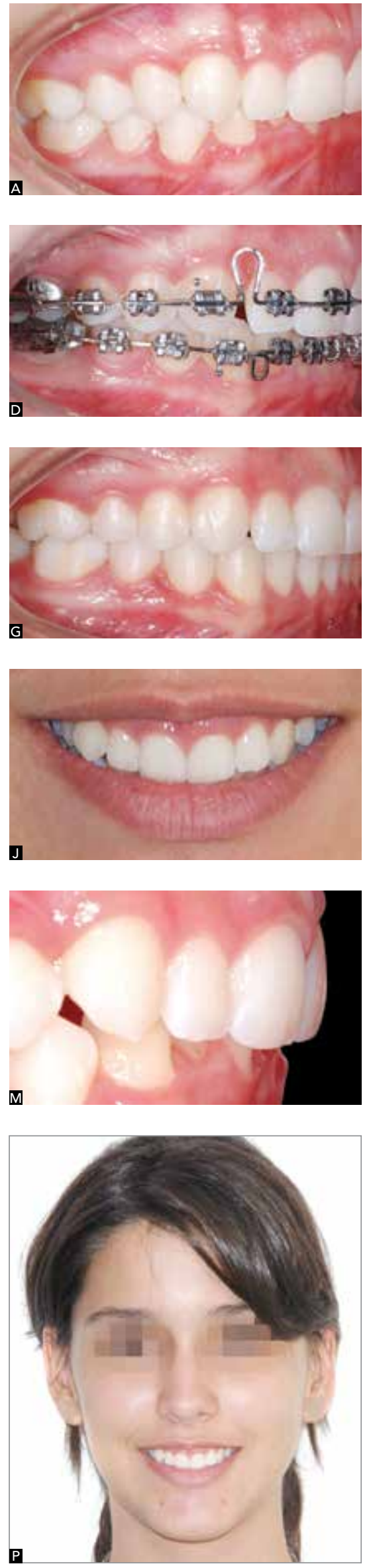
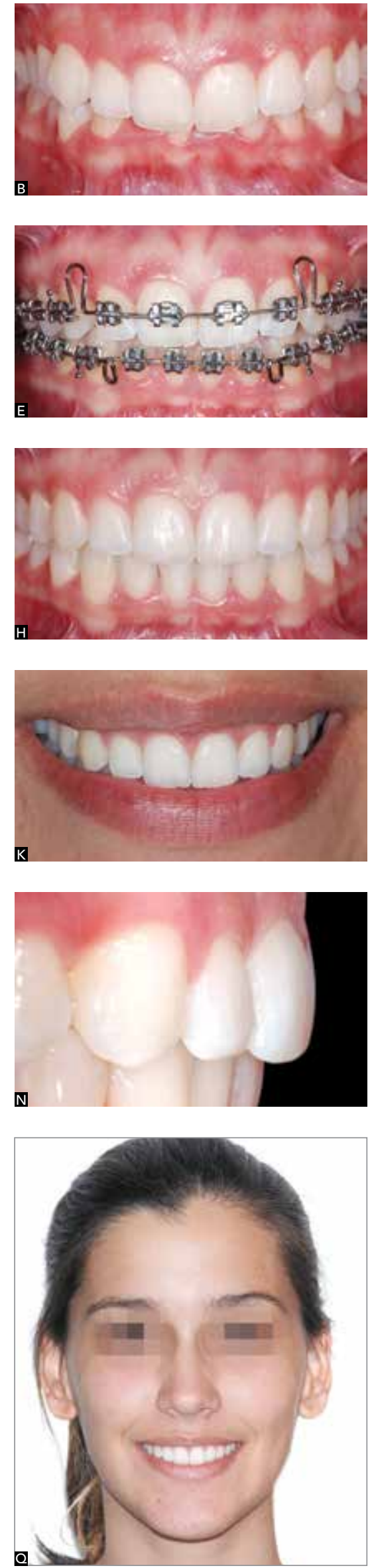
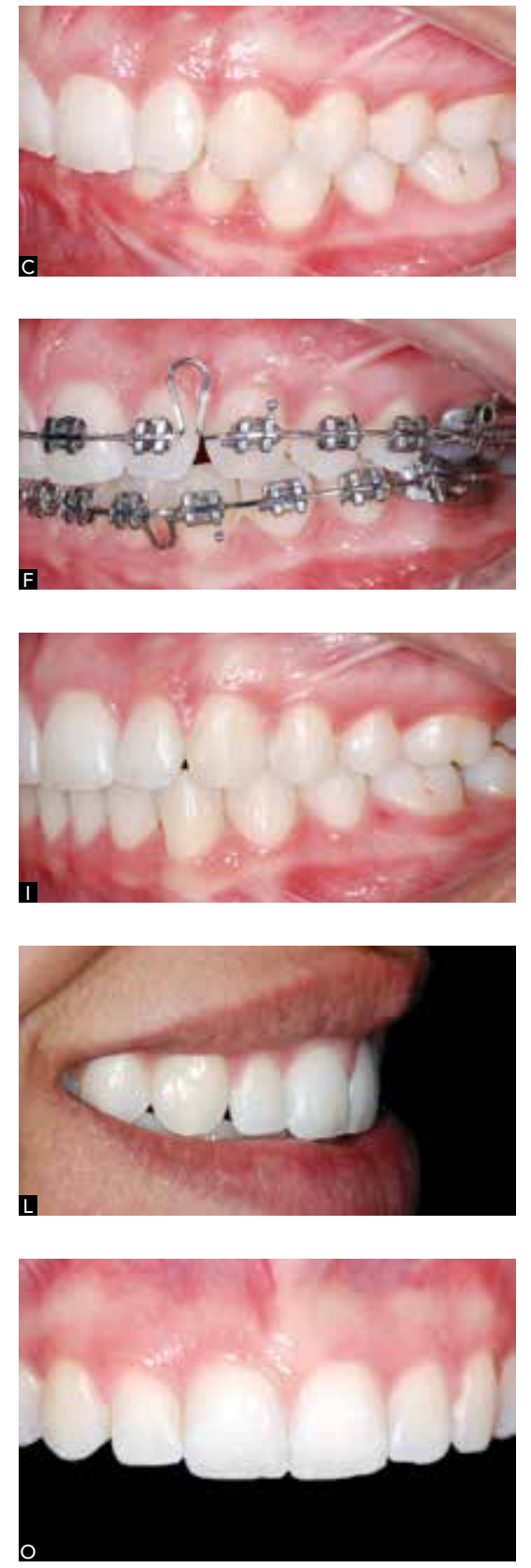

Figure 12 - Angle Class | malocclusion with cephalometric characteristics of Class II division 2. hypertonic musculature. A, B, C) Retroclined and crowded anterior teeth (note flash light "burst" on the cervical of the central incisors). D, E, F) Retraction of upper anterior teeth, with maximum torque control. G, H, I) Finished case, flash "burst" in the middle of the crown of central incisors, indicating ideal torques and occlusal plane parallel to Camper's plane. J) Smile before Orthodontics. K, L) Smile after Orthodontics. M) Lingual inclination of the incisor crowns prior to Orthodontics $\mathrm{N}, \mathrm{O})$ Torque correction, increasing the virtual height of teeth. P, Q) Smiling face, before and after Orthodontics, revealing greater amplitude of the smile after treatment 

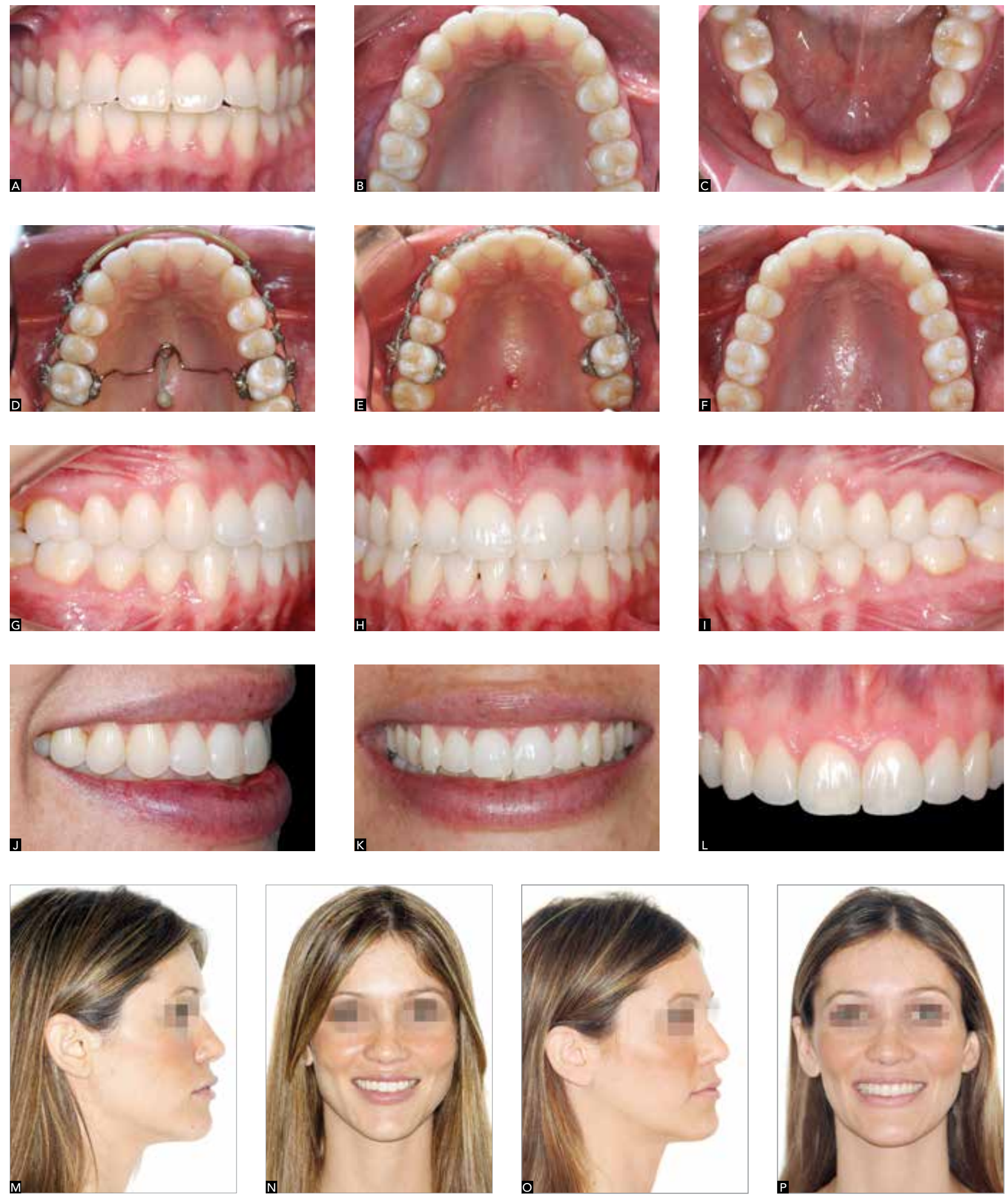

Figure 13 - Patient with Class I malocclusion, in good initial intercuspation. A, B, C) Dental double protrusion, with proclination of incisors revealed by the flash "burst" on the incisal surface of the upper central incisor. Large posterior teeth. D) Mini-implant on the palate, used as anchorage for retraction. E, F) After generous interdental wear on posterior teeth, the incisors were retracted, and the shape of the arches was maintained. G, H, I) Results after Orthodontics, with the "burst" of light in the middle of the crown of incisors. J, K, L) More pleasant smile as a result of torque correction and teeth positioned in the bone bases. M, N) Facial profile and smile before treatment, indicating minimum retraction of the lips. O, P) Face in profile and smile by the end of the treatment, enhancing the patient's beauty. 


\section{DOMINANCE OF CENTRAL INCISORS}

A concept that has been strongly settled in oral prosthetic rehabilitation, specially advocated by Kina and Bruguera, ${ }^{25}$ states that the central incisors must be dominant in the smile in order to provide unity, strength, joviality and sensuality. In a dental composition, the dominance of central incisors is considered natural. Previous studies show that human perception is deviated to the upper central incisors and, when their dominance on the face is increased or emphasized, people are considered as younger and more attractive. ${ }^{25,54}$

The studies carried out by King et $\mathrm{al}^{27}$ showed the preference of dentists, orthodontists and laypeople for the incisal edge of the lateral incisors always being above the incisal plane, on average $0.5 \mathrm{~mm}$, not exceeding $1 \mathrm{~mm}$. This is the pattern used in Orthodontics, with the contour of the incisal edges of the upper anterior teeth following the curvature of the lower lip on the smile. ${ }^{32,49,62}$

Some authors ${ }^{25,26}$ of the Dental Prosthesis field work with greater distances and, therefore, the smile curvature becomes more accentuated. The search for joviality based on dental dimensions has generated some excess, but the orthodontist cannot ignore the trends and convictions of other specialties in Dentistry. With some judgment, and after discussing the theme with the patient and the oral rehabilitation colleague, good results can be obtained with the use of porcelain veneers (Fig 14).

Another procedure employed by Dental Prosthesis, and discussed in the previous special article, is the recommendation of increasing the flat surface area on the morphology of the prosthetic anatomy of the central incisors, expanding the reflection of light and contributing to the dominance of central incisors on the facial dynamic. ${ }^{1,19,36,55}$

\section{HEIGHT OF CONTACT POINTS}

There are some procedures that can really make a difference on the results of treated cases. Smile symmetry and amplitude were already discussed in this article and must be associated with the sensation of depth and naturality when placing the contact points.

The golden ratio is applied to the height of the contact points of the anterior teeth..$^{41,50,52}$ The contact point between central incisors must correspond to $50 \%$ of the height of the crown of these teeth, and must gradually distally reduce, turning into $40 \%$ of this height at the contact point between central and lateral incisors, and $30 \%$ of this height at the contact point between lateral incisor and canine. According to Kina and Bruguera, ${ }^{25} \mathrm{a}$ hypothetical line connecting the ends of the anterior contact points must be parallel to the horizontal lines of the face and to the edge of the lower lip in order to establish a cohesive and harmonious unity of the smile (Fig 15). These lines and proportions were also used in the determination of the "six horizontal smile lines", emphasized by Câmara ${ }^{11}$ and widely used for smile analysis.

There are three ways to achieve this proportion:

1) Prosthetic increase - selective for the height of the crowns of anterior teeth: as it has been previously mentioned, the procedures of Restorative Dentistry and, specially, the porcelain veneers are some of the options that have been increasingly used and resistant to time..$^{2,26}$

2) Gingivectomy including the papilla (Fig 16) the correction of the gingival contour and the ideal height/width proportion of the teeth must be conciliated so as to intervene in the height of the interdental papilla. In this case, the intervention emphasizes the existence of more than $5 \mathrm{~mm}$ of distance between the alveolar bone crest and the contact point, a condition that is established to avoid the opening of black spaces in the interdental spaces. ${ }^{59}$

3) Ameloplasty, performed in two ways - increasing the contact area by interdental wear, or reducing the contact area of the incisal edges, altering the incisal spaces. ${ }^{52}$ The interdental embrasures form interdental angles which, according to Magne and Belser, ${ }^{37}$ are shaped as an inverted "V", narrower between the central incisors, asymmetric between central and lateral and large between lateral incisor and canine (Fig 17).

When the shape of the interincisal angles are changed by ameloplasty, the professional must also consider if it is desirable to change the shape of the teeth, making them rounder, with wider interincisal angle spaces (Fig 18). Women can be specially benefited with this procedure, while marked angles are masculine characteristics that are desired by the evaluators. ${ }^{4}$ The patient must be consulted before this procedure is performed, and the simulation of the future shape of the teeth, drawn with a black dermographic pen, is recommended.

\section{TEETH / PERIODONTIUM RELATION}

The discovery of the importance that "pink esthetics" has on the results of dental treatments is not recent, and the definition of normality has nearly established 

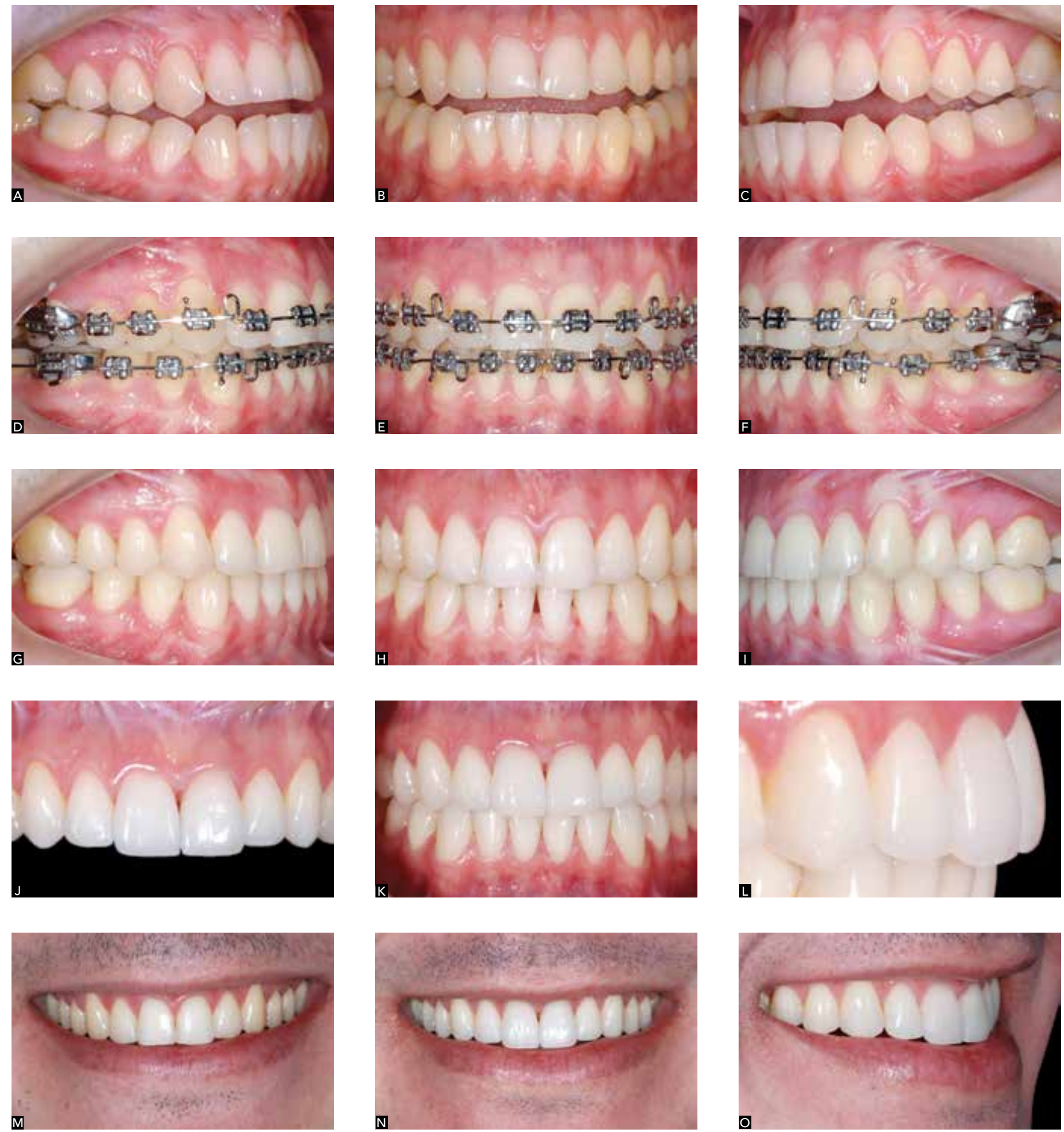

Figure 14 - Class III patient with anterior open bite, referred to orthodontic-surgical treatment. A, B, C) Initial intraoral photographs, revealing loss of height of central incisors, probably caused by chemical erosion. D, E, F) Occlusion established after surgical procedure with maxillary advancement. G, H, I) Result after Orthodontics, in which satisfactory occlusion can be noted, but with incisal curve almost flat. J, K, L) Final result of the patient's microesthetics, with dominance of the central established by means of porcelain veneers. M) Smile after Orthodontics, and before the veneers. N, O) Repercussion on miniesthetics (smile), after veneers on teeth \#11 and \#21: a younger smile. 

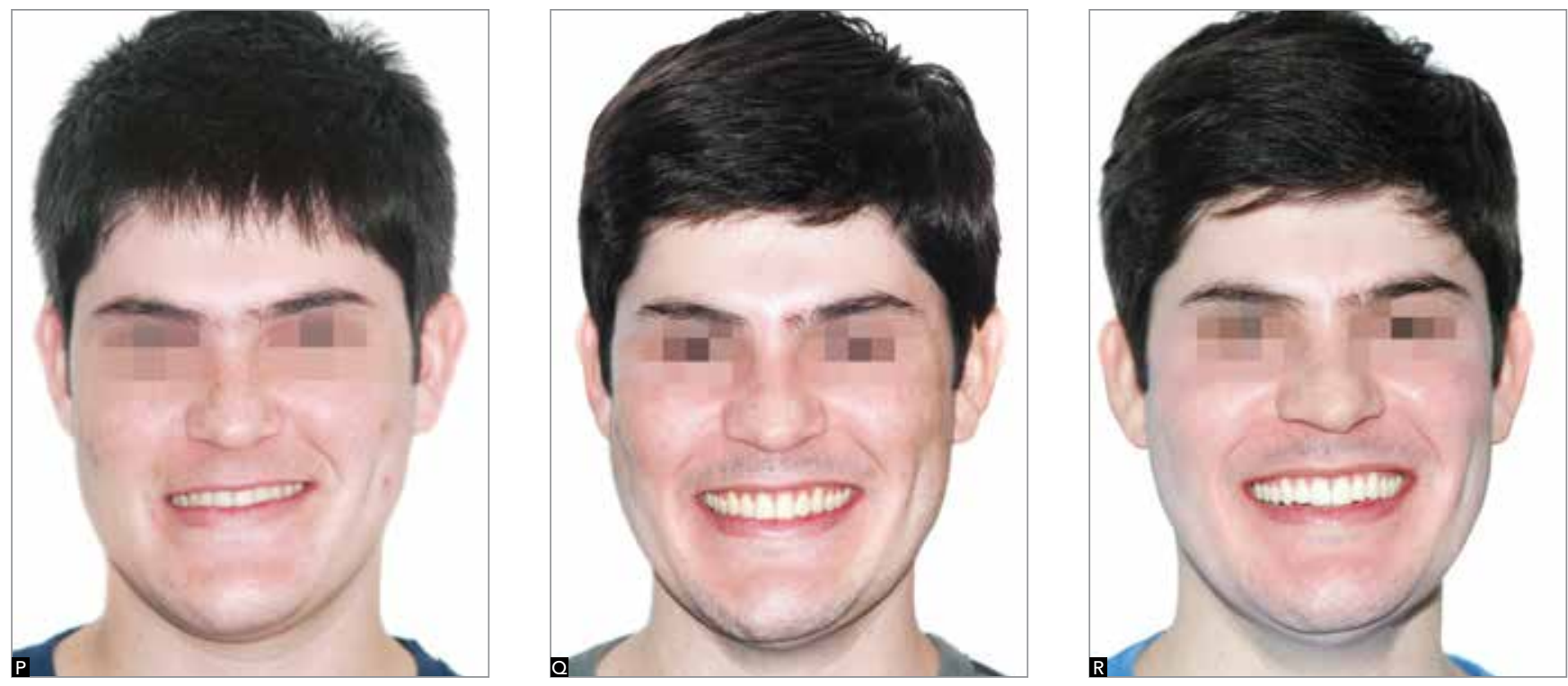

Figure 14 (continuation) - P, Q, R) Macroesthetics (smiling face), sequence of events (left to right): before treatment, after Orthodontics, after veneers.

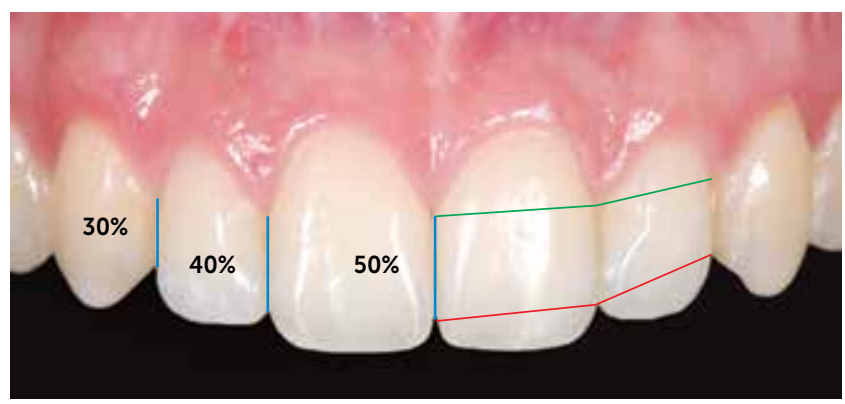

Figure $\mathbf{1 5}$ - Ideal heights of contact points. Between the central incisors, it must be half of the height of the crown of these teeth, decreasing distally, at each contact, always in relation to the central incisor. Guiding lines connecting the apices of the papillae (red) and the lower ends of the contact points (green), emphasized by Câmara. ${ }^{11}$

a consensus among professionals that deal with esthetics. 111,12,13,26,28,34,48,51,61,63 There is an integration between the factors that determine microesthetics, so that when ideal dental proportions and dimensions are established, the relations between the heights of the crowns of upper anterior teeth also define the adequate gingival contour. Furthermore, the problems tend to be correlated, and the solution becomes the intervention on the position of teeth and dental anatomy, alteration of the anatomy of the periodontium or both procedures.

\section{Gingival contour}

Kokich, Nappen and Shapiro ${ }^{28}$ established the parameters that must be sought to obtain gingival contour, with the gingival margin of canines and upper central incisors at the same level, and the margin of upper lateral incisors $1 \mathrm{~mm}$ below those. (Fig 17) The margin of the lateral at the same height of the central is considered acceptable, provided that, in prosthetic procedures, color and shade effects are established to reduce the virtual height of lateral incisors. ${ }^{13,40}$

Evidently, the gingival contour must be considered as esthetically important if there is gingival exposure at smiling, specially when the smile line is high..$^{57}$

When the gingival contour is asymmetric, with difference in the height/width proportion, three situations, with distinct possibilities of performance, must be considered, as described below.

1) If the teeth are higid and the incisal edges are correctly leveled: there is a difference in height between the clinical and anatomical crowns of the tooth, usually related to the excess of gingival tissue. In this case, by means of a periodontal probe,it is noticeable that the gingival sulcus is deep or that he periodontal biological space is excessive. This happens when the keratinized gingiva is thick and did not migrate apically, which defines a partial eruption of the tooth; or when there was gingival hyperplasia, which is very common for orthodontic treatment, specially for patients with poor oral hygiene. ${ }^{33,61}$

In these cases, the patient must be referred to a periodontist for augmentation of the clinical crown of anterior teeth, performed by means of gingivectomy. Depending on the width of the keratinized gingiva area, a gingival flap associated with bone recontouring might be necessary. ${ }^{28}$ The amount of periodontal 

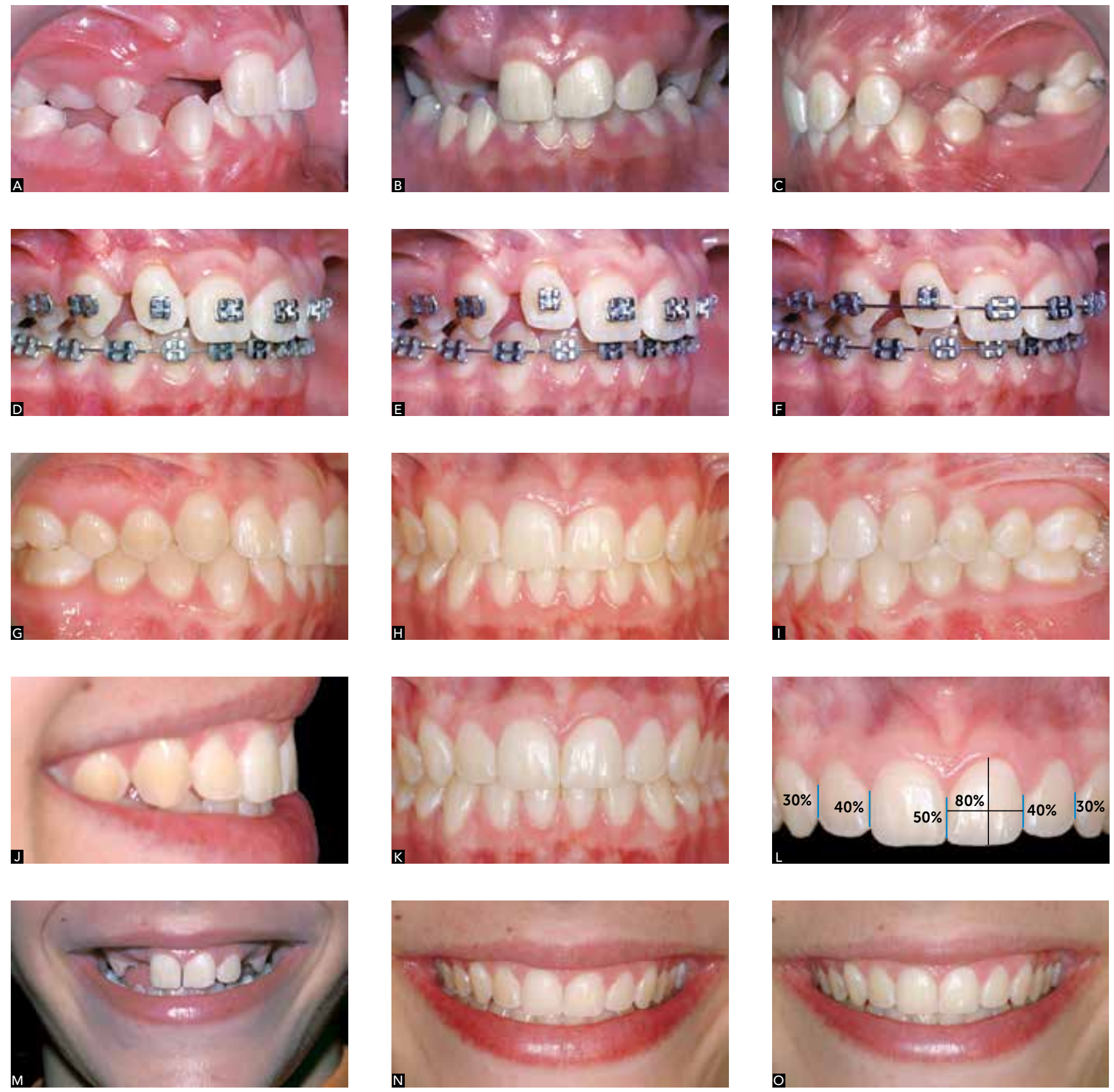

Figure 16 - Adolescent patient, with impacted canine and lateral incisors, without space. A, B, C) Maxilla with atresia, leading to right posterior crossbite, upper midline deviated to the right. D, E, F) After the lateral incisor had been forcefully extruded, ameloplasty was performed on the incisal surface in addition to cervically rebonding the bracket, allowing greater extrusion and correction of the gingival contour. G, H, I) Result obtained after Orthodontics, with satisfactory occlusion, but with difference in the height of the contact points and gingival contour of the left upper central incisors. J, K, L) Results after gingivectomy, including the papilla between teeth \#21 and \#22, to redimension the crown of tooth \#21 and the contact point. M) Smile before Orthodontics. N) Smile after Orthodontics. O) Smile harmony after gingivectomy 

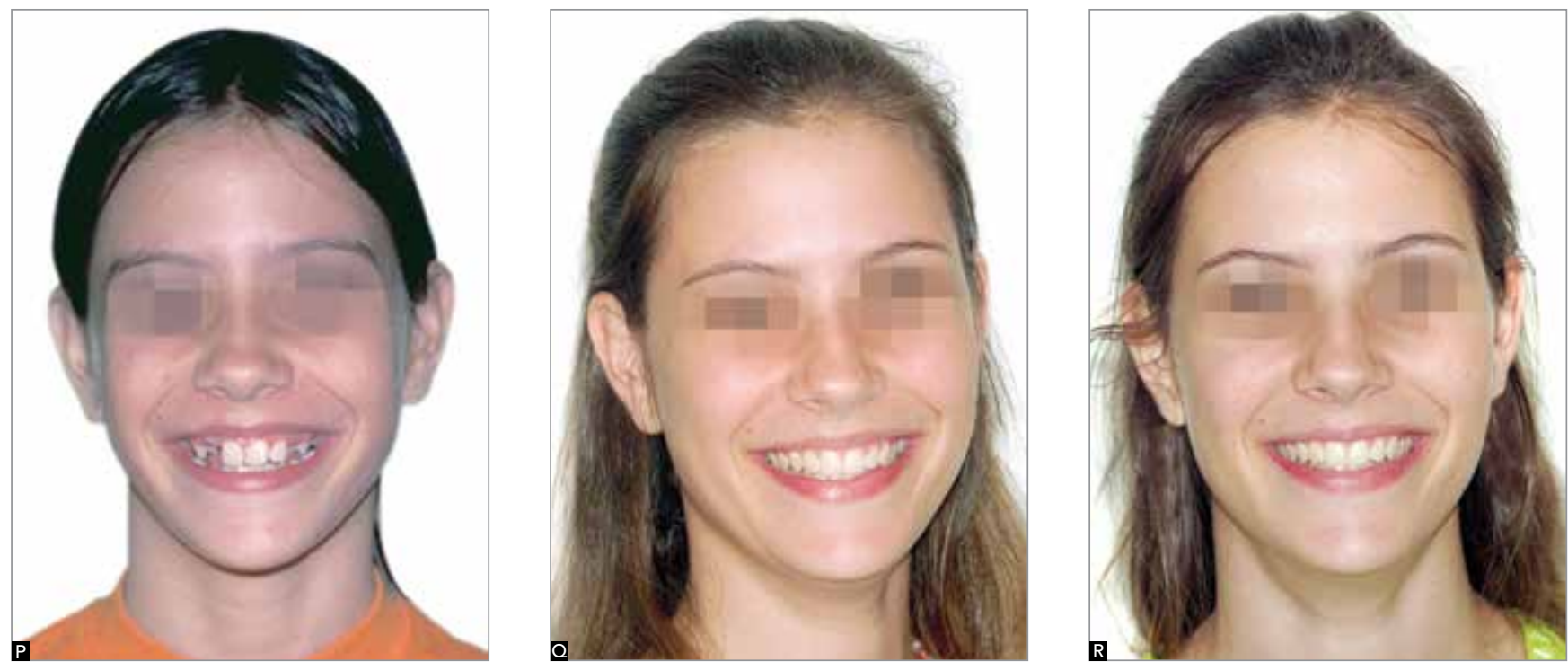

Figure 16 (continuation) - Smile before $(\mathbf{P})$ and after orthodontic treatment $(\mathbf{Q})$. R) Smile harmony after gingivectomy.

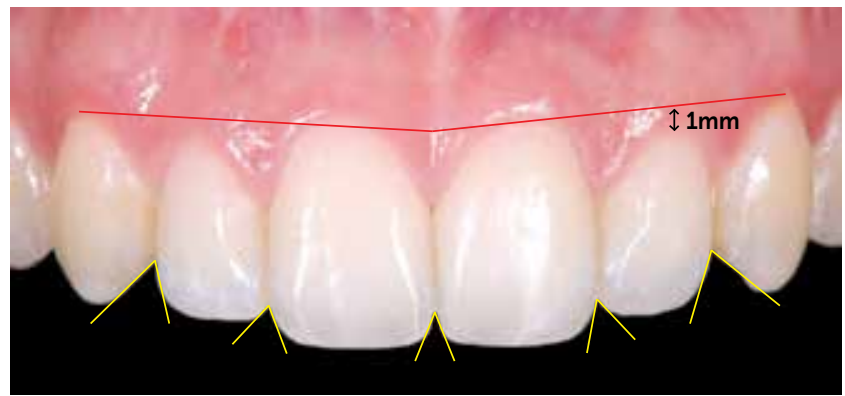

Figure 17 - Gingival contour and spaces. The red line shows the gingival contour, with lateral incisor $1 \mathrm{~mm}$ below the apical limit of the contour of the central incisor and the canine. In yellow, the conformation in inverted " $\mathrm{V}$ " in the interdental spaces, defined as: narrow between central incisors, asymmetric between central and lateral, and large between the lateral incisor and canine.

tissue that will be removed corresponds to what is enough to establish the best height/width proportion, along with the best gingival contour relation. In higid teeth, the exposure of the entire anatomical crown is recommended.

It is worth noting that, after surgery, the tooth seems to be greater in height in comparison to what it will actually be after three months, which is the period necessary for the operated gingiva to recover and for the gingival sulcus to be restored, reducing the crown height in nearly $2 \mathrm{~mm}$. Patients with gingival smile are specially benefited by this procedure.

2)If the teeth are not higid: there usually is asymmetric wear of the incisal edges, associated with compensatory extrusion of these teeth, together with the entire periodontium of the compromised tooth. In these cases, the leveling of cementoenamel junctions must be carried out with individualized intrusion movements. ${ }^{30,34}$ The appliance must be placed in compliance with the need for gingival contour correction, and not the leveling of incisal edges. ${ }^{62}$ It is very important to emphasize that the intruded tooth needs to be retained for, at least, six months in its position, waiting for the turnover of the periodontal ligament, when the stretched collagen and elastic fibers are rearranged, reducing the risk of relapse. The importance of Orthodontics for the solution of periodontal and prosthetic problems was clearly exposed in the systematic review published by Gkantidis, Christou and Topouzelis. ${ }^{21}$

Esthetic restorative procedures will be necessary to establish the relation of incisal edges and dental proportions by means of composite or provisional resin during orthodontic finishing. It is also important to consider that there might be accumulation of gingival tissue with the intrusion of the tooth, which will indicate that a gingivectomy procedure should be performed at least three months before the definitive prosthetic work is performed. ${ }^{63}$

3) If there is a bone defect: usually associated with a history of periodontal disease or localized gum recession, making the gingival edge of a tooth to move apically. In this case, slow dental extrusion is indicated, 

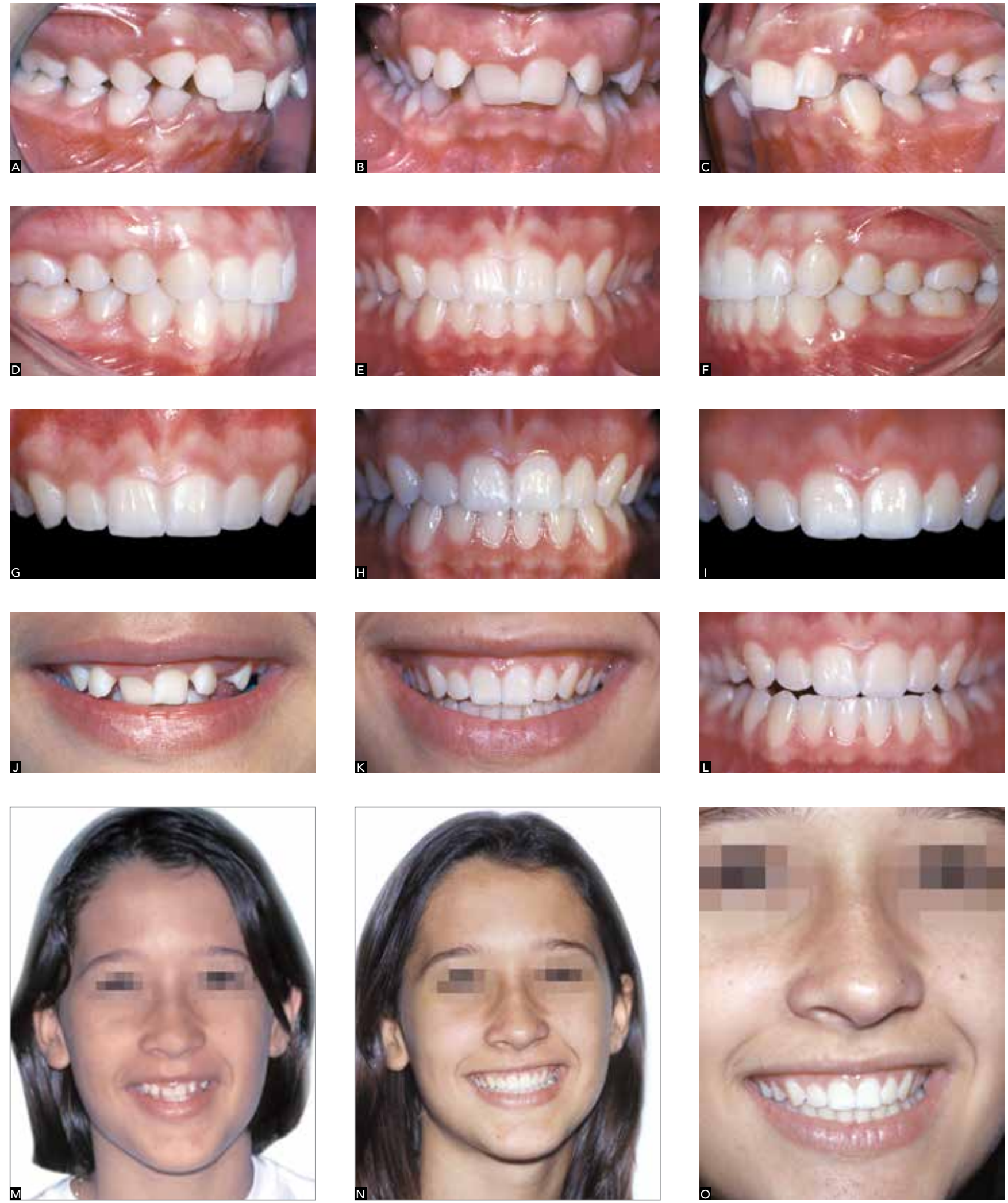

Figure 18 - Angle Class II division 2 malocclusion. A, B, C) Retroclined upper central incisors and overbite, characteristics of malocclusion. D, E, F, G) Treated case, with good arch relationship, the aspect of fused teeth on the upper central incisors calls our attention because of the very large contact point. $\mathrm{H}$, I) After ameloplasty, which increased the incisal spaces, resulting in reduction in the height of the contact points between the central incisors, and their progressive distal decrease. J, M) Smile before treatment. K, L, N, O) Smile after Orthodontics and ameloplasty, resulting in rounder incisal edges and larger spaces. 
followed by wear of the incisal edge. ${ }^{21}$ In order to use the root of the extruded tooth, the limit of extrusion is the minimum crown/root relation (1:1). The tooth can be slowly extruded above this limit, with its extraction previously planned and with the aim of achieving alveolar bone and/or gingival soft tissue gain for posterior placement of implant. ${ }^{30,57}$ Current scientific evidence reveals that additional studies are warranted so as to obtain predictability of periodontal response for correction of bone defects through orthodontic movement. ${ }^{46}$

One of the greatest concerns about gingival contour is with regard to implants and facial growth. It is known that the end of growth, which was believed to be at 16 years of age for girls and 18 years for boys, in fact does not happen. There is a late growth, with sudden changes, which is especially important for young adults between 17 and 23 years of age, that must be considered. ${ }^{5}$ The consequences of vertical growth for gingival contour are known. Unlike the teeth, the implants do not follow the displacement of maxillary bones, producing important asymmetry on gingival and incisal contours (Fig 19). In these cases, the esthetic concern is even greater because implant substitution, of which gingiva migrates apically as time goes by, is not a simple procedure, and may generate a bone defect that is difficult to solve. The decision on placing implants in the anterior region must consider the height of the patient's smile line and, in particular, estimate the vertical facial growth. ${ }^{60}$

Mishandling orthodontic treatment may cause potential gingival defects when there is buccal root movement, especially in critical areas or in patients with thin periodontal biotype. ${ }^{43}$ On average orthodontic treatments, periodontal recession and alveolar bone loss are minimum $(0.03 \mathrm{~mm}$ and $0.13 \mathrm{~mm}$, respectively), as showed in the systematic review published by Bollen et al. ${ }^{6}$

\section{Zenith}

The gingival zenith is the highest point of the gingival contour curvature, and may vary significantly in anterior teeth. ${ }^{62}$ Sarver ${ }^{50}$ presents as norm that the ideal position of the apex of the gingival contour of the lateral incisor would be in the center of the crowns, along the long axis of the tooth; while it is distally displaced on the central incisor and canine.

In recent research, Chu et al. ${ }^{13}$ quantified the position of the gingival zenith of upper anterior teeth in a periodontally healthy population: $1 \mathrm{~mm}$ distal to the line that divides the middle of the crown, following the long axis of the tooth, on the upper central incisor; $0.4 \mathrm{~mm}$ distal to the line that divides the middle of the crown, following the long axis of the lateral incisor; and at the center of the line that represents the long axis of the upper canine (Fig 20).

The zenith can be orthodontically defined by the position of the bracket bonded to the upper anterior teeth or second-order bends on orthodontic wires, also known as artistic bends that define the mesiodistal tippings of these teeth. On the other hand, if we consider the mesiodistal angulation patterns which are used for the anterior teeth, the greatest tipping is established for the lateral incisors and canines which have the zenith less distally displaced if compared to the central incisor. The limit of what is esthetically pleasant for zenith deviations, in relation to the center of the upper central incisor, seems to be $2 \mathrm{~mm}$, coinciding with a mesial tipping of 10 degrees from the long axis of these teeth. ${ }^{22}$

Prosthetically, the volume of the crown may contribute to the apical displacement of the gingival margin, and the coloration or shade in the cervical region of the tooth may generate the optical illusion of the most apical part of the gingival contour of each tooth - which is not simple, specially due to the need for a refined interaction between the technician in prosthesis and the prosthodontist. ${ }^{37}$

Definitely, the zenith represents an intrinsic characteristic of the periodontium and, therefore, can be more easily modified by periodontal surgery, with clinical crown augmentation; or recovering, in cases of periodontal recession. The stability of the position defined by the periodontist depends on respecting the periodontal biological space and the architecture of the alveolar bone crest which can be defined by bone recontouring. ${ }^{18} \mathrm{Chu}^{15}$ emphasizes the use of the proportionality gauge developed by him for this purpose, using the vertical point, which defines $3 \mathrm{~mm}$ of interval between the colors of the two segments that compose the end of the instrument to guide the professional on establishing the alveolar bone limit in the cervical area of periodontally modified teeth (Fig 5).

Maximum symmetry on the placement of the zenith is recommended, specially on the upper central incisors due to the proximity established between them as well as to the facial midline..$^{25}$ 

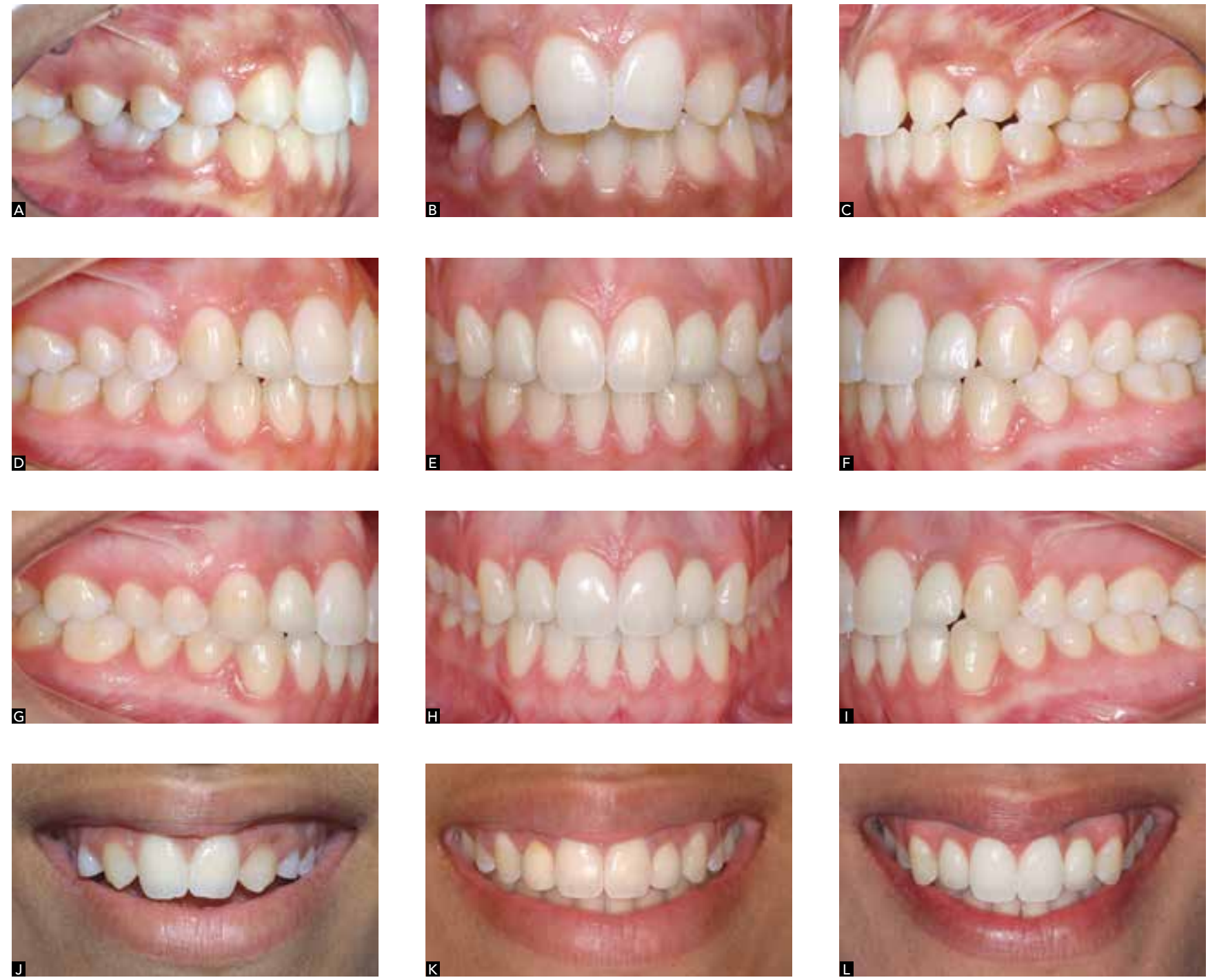

Figure 19 - Patient with agenesis of upper lateral incisor, who decided for dental implant. A, B, C) Initial photographs, showing the mesialization of permanent upper canines and the prolonged retention of deciduous canines. D, E, F) Orthodontic correction opening spaces by distalization of canines for placement of osseointegrated implants and crowns, at 20 years of age. G, H, I) 26-year-old patient: note that the levels of gingival and incisal contour of the implants rose at least $1 \mathrm{~mm}$. J, K, L) Sequence of photographs of the smile in different moments: before treatment, soon after Orthodontics with implants, and 6 years after implant placement, with canines quite marked by the infraocclusion of lateral incisors. 


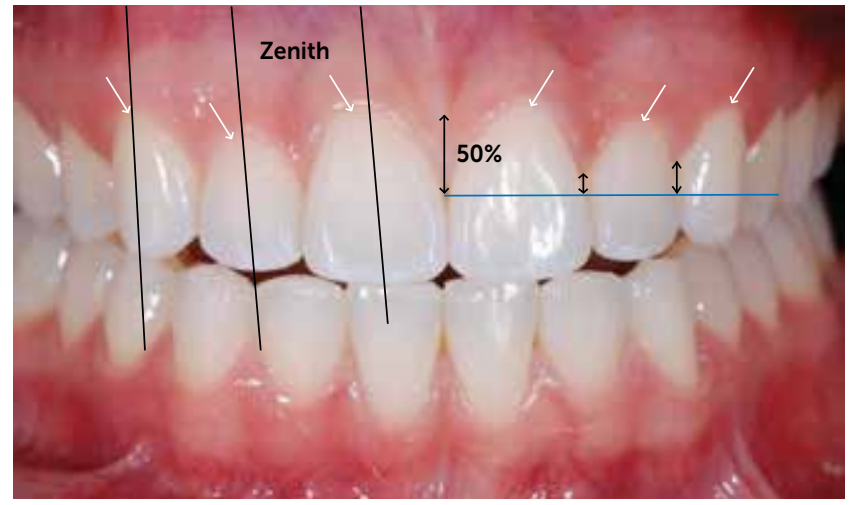

Figure 20 - Zenith and gingival papillae. Arrangement of the zenith defined by the inclinations of the long axis of the upper anterior teeth: in the middle of the canine, $0.5 \mathrm{~mm}$ distal to the lateral incisor; and $1 \mathrm{~mm}$ distal to the central incisors (white arrows). Papilla between the central incisors filling the space until half of the height of the crowns of these teeth and gradually reducing, in height, to distal.

\section{Height of the papilla / black spaces}

The gingival papilla must apically fill from the interdental space to the contact point, being extended to half of the height of the upper central incisor, and following a position that is gradually more apical from the midline on, conferring a natural and beautiful aspect to the smile (Fig 20).

When the distance between the roots is shorter than $0.3 \mathrm{~mm}$, it affects the presence of the proximal bone and, therefore, is usually accompanied by the absence of the interdental papillae On the other hand, greater interradicular spaces, as in the diastema, are usually associated with short and flattened papillae.

Tarnow, Magner and Fletcher ${ }^{59}$ showed that the interdental papilla is present in $98 \%$ of the cases in which the cervical limit of the interdental contact is located up to $5 \mathrm{~mm}$ from the alveolar bone crest. When the distance from the contact point to the bone crest is of $6 \mathrm{~mm}$, there is nearly $50 \%$ of chance of black space; and with $7 \mathrm{~mm}$ of distance, the presence of interdental papilla filling the space is found in only $27 \%$ of the cases. Therefore, it is possible to predict the appearance of black interdental spaces, which are especially common in patients with triangular teeth, when severe crowding is corrected or when there is bone loss by periodontitis.

Orthodontics has used the procedure of interdental wear for the closure of these spaces, changing the dental shape and, thus, approximating the contact point of teeth and the alveolar bone crest. ${ }^{33,53,61}$ This procedure, extremely common among orthodontists, may lead to other undesirable esthetic consequences. Interdental wear changes two determinants of esthetics: 1) height/width proportion of the crowns, possibly generating excessively narrow teeth, and 2) increase in the height of the contact point, breaking the golden ratio of the smooth reduction in the distal direction.

A good guide to define the correct attitude towards interdental black spaces is, in ascending order of procedure:

1) Interproximal wear until the width of the incisor is not smaller than $80 \%$ of its width, in which case $75 \%$ is acceptable for naturally elongated teeth and faces.

2) Restorations or porcelain veneers changing the dental anatomy up to the limit of proportions in height of the contact points.

3) Periodontal surgery with graft to increase the height of the papilla, which is left as a last resource due to the fact that the prognosis is not always favorable.

The case presented in Figure 21 shows the closure of the pathological diastema in a periodontally compromised patient, followed by wear up the limit of the dental proportions, and finishing with veneers that closed the interdental black spaces.

\section{PROPORTIONS BETWEEN DENTAL ARCHES (BOLTON DISCREPANCY)}

A special part of this article was reserved to discuss a fundamental and specific procedure of Orthodontics, which is the analysis of Bolton discrepancy. ${ }^{7}$ Additionally, it aimed at discussing the clinical development of this problem of high prevalence in the population, equally distributed in both genders and in different ethnicity and types of malocclusion. ${ }^{23}$

Although it is seen as a mathematical calculation for orthodontic planning that aims at establishing a better relation of the mesiodistal dimensions between the upper and lower arches, the discrepancy of dental volume must be carefully considered. Attenuating this difference is fundamental to establish satisfactory dental intercuspation, but, on the other hand, the problem can also be aggravated by wrong professional decisions. The fact that the measurements taken in models to define dental volume discrepancy show poor reliability deserves attention, with regard to measurement errors in cases of crowding over $3 \mathrm{~mm} .{ }^{56}$ 

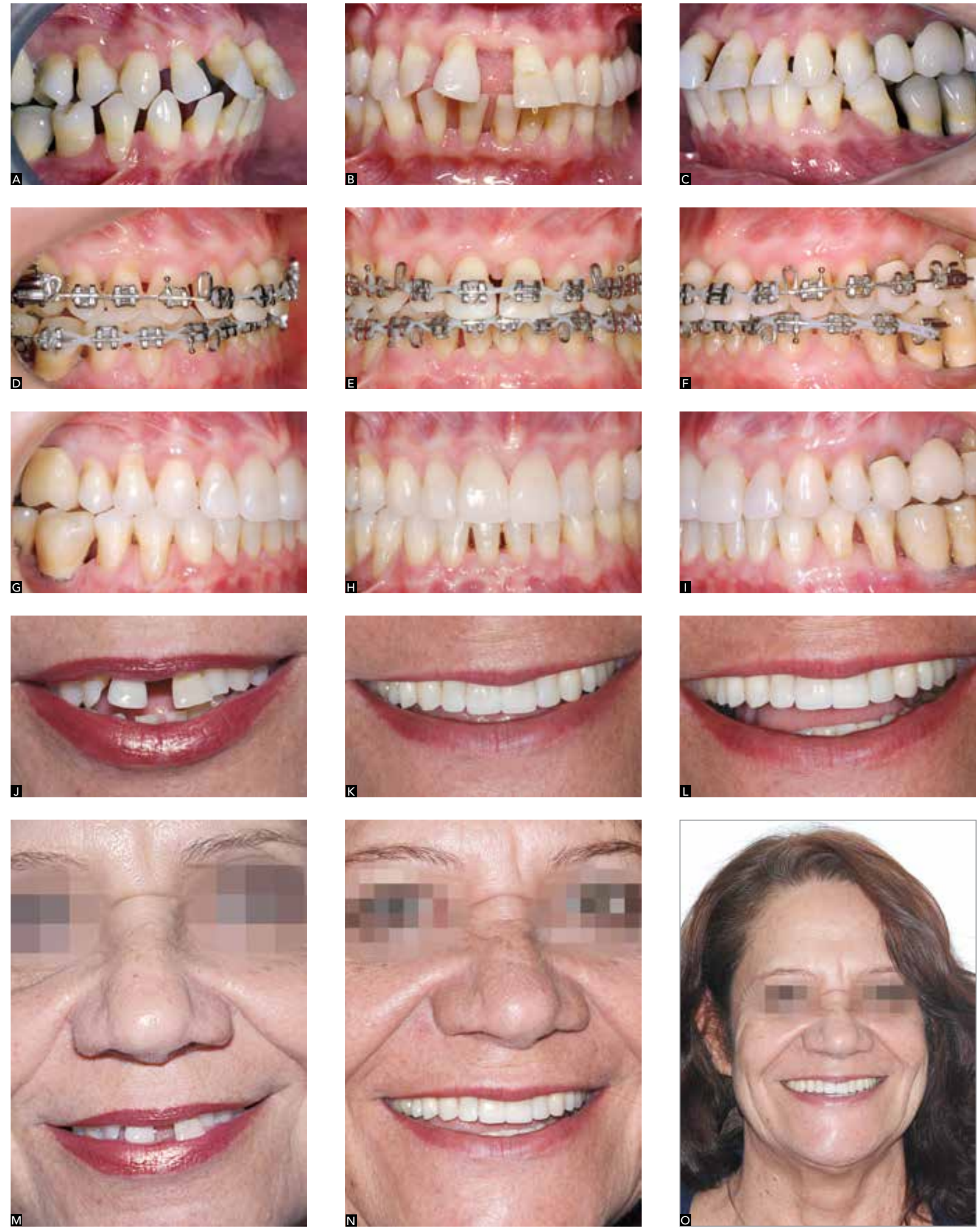

Figure 21 - Patient with history of aggressive periodontitis which was periodontally treated and controlled. A, B, C) Initial malocclusion, with dental loss, pathological tooth migration and multiple diastema. D, E, F) Ongoing orthodontic treatment, with interdental wear at the limit of the height $x$ width proportion, for closure of black spaces, within the best dental proportion. Posterior teeth still in provisional, with precarious anatomy. J, M) Smile before orthodontic treatment. K, L, N, O) Smile after perio-ortho-prosthetic integrated treatment, in several amplitudes and approaches. 
Dental volume addition was described in the first part of this article, with space opening performed to restore dental width (Fig 3). Most of the times, the professional decides to reduce dental volume in one of the arches by means of interdental wear or atypical extractions.

Decisions on incisors extractions should be previously tested by physical or virtual set-up, because the calculations do not contemplate the buccolingual thickness of the incisal edges. Moreover, small differences may be disguised by differentiated torques and variations of overbite. ${ }^{29}$ The orthodontist may cause a large Bolton discrepancy when extraction of a lower incisor is planned (usually recommended to treat lower anterior crowding) and not previously tested. In extreme cases, a new malocclusion would be created by the orthodontist, which would result in a contracted lower arch, canines without contact and accentuated overjet and overbite.

The attenuation of the Bolton discrepancy by means of wear also needs to be considered, because, in cases in which the dimensions of upper incisors are at the limit of the height/width dental proportion or present square-shaped crowns, the wear is quite limited, for it causes dangerous root proximity and quite extensive contact points in the cervico-incisal height. ${ }^{29}$ The Bolton discrepancy is an important and decisive finding for orthodontic treatment and, beyond numbers, it presents clinical unfolding. Because it is a mathematical estimate, its clinical implications must be considered. Some logical rules can be used to guide the orthodontist's conduct, showing the problem and solving it as the treatment evolves.

Clinically, the best treatment option should privilege molar intercuspation as the first step of treatment. After the distobuccal cusp of the upper first molar is occluded between the lower first and the second molars, the spaces are closed backwards, and some situations may appear:

1) If the relation is canine Class II after premolars have been distalized and occluded: it shows upper posterior excess, and it can be solved with interproximal wear on the mesial surface of the first molar; mesial and distal of premolars; and on the distal surface of upper canines.

2) If the relation is canine Class III after premolars have been distalized and occluded: it shows lower posterior excess, and it can be solved with interpoximal wear on the mesial surface of the first molar; mesial and distal of premolars; and on the distal of lower canines.

3) If overjet or anterior crossbite persists after premolars have been distalized and occluded, and after canine occlusion has been defined: it shows lower anterior excess, and it can be solved with interproximal wear on the mesial surface of the canines and on the mesial and distal surface of lower incisors.

4) If overjet persists after premolars have been distalized and occluded, and after canine occlusion has been defined: it shows upper anterior excess, and it can be solved with interproximal wear on the mesial surface of canines and on the mesial and distal surfaces of upper incisors - respecting the ideal symmetry and proportions. In this case, the lack of lower anterior dental volume must be verified and the need for incisor clinical crown augmentation must be considered.

Clinical conditions may present a blend of these possibilities of solution, and the excess may also be by quadrants, with asymmetry between the right and left sides. A careful analysis of the relation of the inclined planes of the teeth in the clinical evaluation, as well as in the analysis of models, can determine if there is significant Bolton discrepancy, without the necessity of applying any formulas, as shown in Figure 22.

\section{CONCLUSIONS}

Microesthetics comprises treatment approaches that are more directly related to Orthodontics and other dental specialties that deal with esthetics. Mastering it must be part of the foundations on which a dentist's fine practice is based. The challenge is to use all the parameters available, those emphasized by the different specialties of Dentistry, and apply these concepts in each treated case. It is not a single detail that defines excellence, but the sum of many of them. This article aimed at describing the ideal dental proportions and dimensions, and their interaction with the periodontium, which shall be considered by the orthodontist for treatment finishing. Many of these aspects are out of the spectrum of changes that the orthodontic appliance could provide and totally dependent on the intervention of periodontists and prosthetists. Therefore, it is necessary to gather concepts and define patterns that must be followed by the team of professionals in order to avoid wasting time with unnecessary or contradictory procedures. 

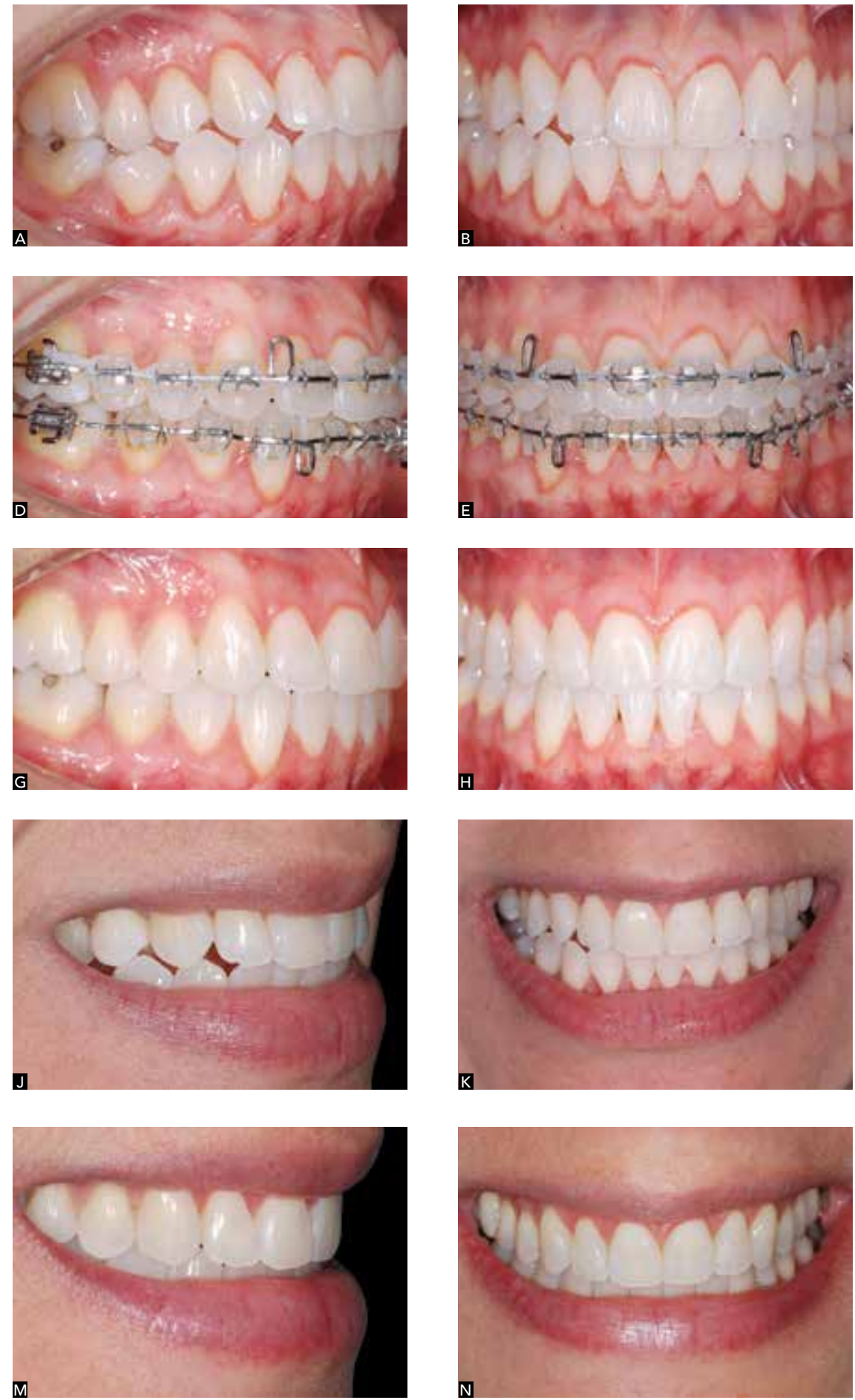

Figure 22 - Orthodontic retreatment case; previous treatment finishing was not adequate, because the proportions between the arches was not observed. A, B, C) Right lower crowding and Class III canine relationship on the left denote bilateral posterior lower excess, whereas Class II canine relationship on the right and the insufficient overjet reveal anterior lower excess. D, E, F) Case being treated with interproximal wear from molar to molar (do not use bands). G, H, I) Orthodontics final result, with satisfactory intercuspation and overbite. J, K, L) Smile and incisor relation before Orthodontics. M, N, O) Final smile and correction of overbite and overjet.
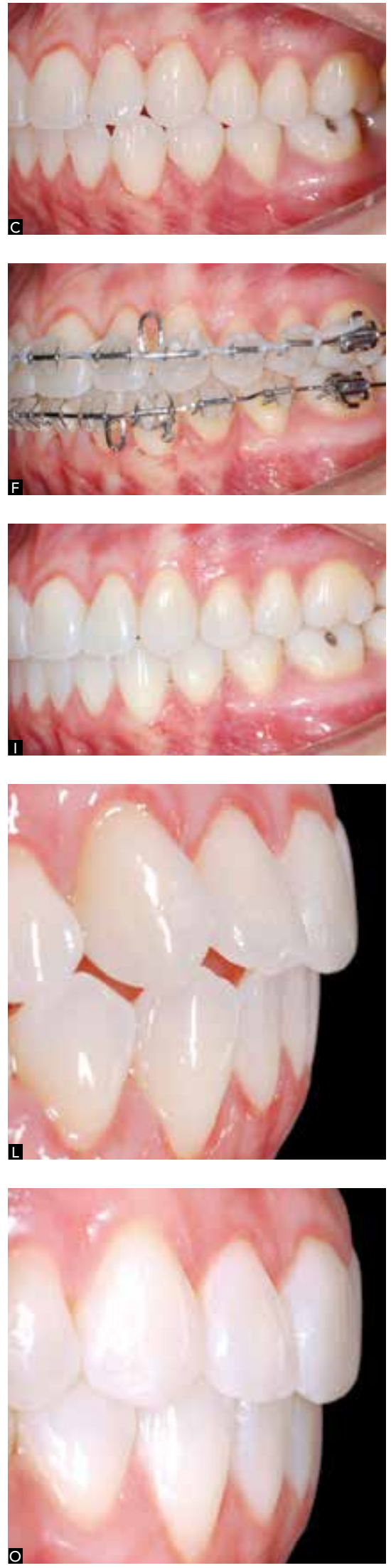
On the clinical tables of cases approved by the American Board of Orthodontics (ABO) and by the Brazilian Board of Orthodontics $(\mathrm{BBO})$, which are presented in meetings, is the phrase: "All cases orthodontically treated have some defects, and the cases herein exposed represent the effort of the professionals to achieve the certification of excellence." This means that the complete excellence in all treated cases should always be sought, even if it is utopian. If all cases are prepared as if they were presented to the $\mathrm{BBO}$ exam, many of them would certainly not achieve the excellence degree for many reasons, but there would be an orthodontist who is much better in his clinical performance, ready to achieve the certification of excellence.

Microesthetics must not be seen in isolation, but as the key to achieve a pleasant smile (miniesthetics) and a harmonious face (macroesthetics). The greatest concern must always be the patient, with his desires not only granted, but overcome by the professional. Our concerns and actions are measured in millimeters, but can make all the difference to people's quality of life. To raise one's self-esteem by means of integrated dental treatment could be considered an objective, that may be referred to as "hyper-esthetics".

\section{ACKNOWLEDGEMENTS}

The authors would like to thank and honor Vincent G. Kokich who represented not only the search for excellence in Orthodontics, with his brilliant articles and lectures, but mainly the critical thinking and the search for the best scientific evidence that must guide the decisions that we need to make every day in our clinics. Special acknowledgements to Telma Martins de Araújo, Lícia Pacheco Teixeira and Gabriela Cassaro de Castro for the precious help on the elaboration of this work.
1. Adolfi D. Natural esthetics. Chicago: Quintessence; 2003.

2. Adolfi D. Functional, esthetic, and morphologic adjustment procedures for anterior teeth. Quintessence Dent Technol. 2009:32:153-68.

3. Al-Johany SS, Alqahtani AS, Alqahtani FY, Alzahrani AH. Evaluation of different esthetic smile criteria. Int J Prosthodont. 2011;24(1):64-70.

4. Anderson KM, Behrents RG, McKinney T, Buschang PH. Tooth shape preferences in an esthetic smile. Am J Orthod Dentofacial Orthop. 2005:128(4):458-65.

5. Behrents RG. Growth in aging craniofacial skeleton. Monograph 17 Craniofacial Growth Series, Center for Human Growth and Development. Ann Arbor, Michigan: The University of Michigan; 1985

6. Bollen AM, Cunha-Cruz J, Bakko DW. Huang GJ, Hujoel PP. The effects of orthodontic therapy on periodontal health: a systematic review of controlled evidence. J Am Dent Assoc. 2008;139(4):413-22.

7. Bolton WA. Disharmony in tooth size and its relation to the analysis and treatment of malocclusion. Angle Orthod. 1958;28(3):113-30.

8. Brandão RCB, Brandão LBC. Ajuste oclusal na Ortodontia: por que, quando e como? Rev Dental Press Ortod Ortop Facial. 2008;13(3):124-56

9. Brandão RCB. Entrevista com Roberto Carlos Bodart Brandão. Rev Dental Press Ortod Ortop Facial. 2009;14(6):19-41.
10. Câmara CALP. Estética em Ortodontia: diagramas de referências estéticas dentárias (DRED) e Faciais (DREF). Rev Dental Press Ortod Ortop Facial. 2006:11(6):130-56.

11. Câmara CALP. Estética em Ortodontia: seis linhas horizontais do sorriso. Dental Press J Orthod. 2010;15(1):118-31.

12. Chiche GJ, Pinault A. Estética em próteses fixas anteriores. 1a ed. São Paulo: Ed Santos: 1996.

13. Chu SJ, Tan JH-P, Stappert, CFJ, Tarnow, DP. Gingival zenith positions and levels of the maxillary anterior dentition. J Esthet Restor Dent. 2009:21(2):113-20.

14. Chu SJ. Range and mean distribution frequency of individual tooth width of the maxillary anterior dentition. Pract Proced Aesthet Dent. 2007:19(4):209-15.

15. Chu SJ. A biometric approach to predictable treatment of clinical crown discrepancies. Pract Proced Aesthet Dent. 2007:19(7):401-9.

16. Dürer A. The art of measurement. San Francisco: Alan Wofsy Fine Arts; 1981.

17. Duthie J, Bharwani D, Tallents RH, Bellohusen R, Fishman L. A longitudinal study of normal asymmetric mandibular growth and its relationship to skeletal maturation. Am J Orthod Dentofacial Orthop. 2007:132(2):179-84. 
18. Fletcher P. Biologic rationale of esthetic crown lengthening using innovative proportion gauges. Int J Periodontics Restorative Dent. 2011; 31:523-32.

19. Fradeani M. Esthetic analysis: a systematic approach to prosthetic treatment. Chicago: Quintessence Books; 2004.

20. Gillen RJ, Schwartz RS, Hilton TJ, Evans DB. An analysis of selected normative tooth proportions. Int J Prosthodont. 1994;7(5):410-7.

21. Gkantidis N, Christou P, Topouzelis N. The orthodontic-periodontic interrelationship in integrated treatment challenges: a systematic review. J Oral Rehabil. 2010:37(5):377-90.

22. Janson G, Branco NC, Fernandes TM, Sathler R, Garib D, Lauris JR. Influence of orthodontic treatment, midline position, buccal corridor and smile arc on smile attractiveness. Angle Orthod. 2011:81(1):153-61.

23. Johe RS, Steinhart T, Sado N, Greenberg B, Jinge S. Intermaxillary toothsize discrepancies indifferent sexes, malocclusion groups, and ethnicities. Am J Orthod Dentofacial Orthop. 2010;138(5):599-607.

24. Karring T, Nyman S, Thilander B, Magnusson I. Bone regeneration in orthodontically produced alveolar bone dehiscences. J Periodontal Res. 1982:17(3):309-15

25. Kina S, Bruguera A. Invisível: restaurações estéticas cerâmicas. 1a ed Maringá: Dental Press; 2007

26. Kina S, Romanini JC, Harmonia. Rev Dental Press Estét. 2007:4(2):67-88.

27. King KL, Evans CA, Viana G, BeGole E, Obrez A. Preferences for vertical position of the maxillary lateral incisors. World J Orthod. 2008;9(2): 147-54.

28. Kokich VG, Nappen DL, Shapiro PA. Gingival contour and clinical crown length: their effect on the esthetic appearance of maxillary anterior teeth. Am J Orthod. 1984;86(2):89-94.

29. Kokich VG, Shapiro PA. Lower incisor extraction in orthodontic treatment. Angle Orthod. 1984;54(2):139-53.

30. Kokich VG, Spear FM. Guidelines for managing the orthodontic-restorative patient. Semin Orthod. 1997:3(1):3-20.

31. Kokich VG, Spear FM. Interdisciplinary management of anterior guidance: a case report. Adv Esthet Inter Dent. 2007;3(3):2-6.

32. Kokich VG. Esthetics and anterior tooth position: an orthodontic perspective. Part I: crown length. J Esthet Dent. 1993;5(1):19-23.

33. Kokich VG. Esthetics: the Orthodontic-Periodontic restorative conection Semin Orthod. 1996:2(1):21-30

34. Kokich VG. Excellence in finishing: modifications for the perio-restorative patient. Semin Orthod 2003:9(3):184-203.

35. Kokich VO Jr, Kiyak HA, Shapiro PA. Comparing the perception of dentists and lay people to altered dental esthetics. J Esthet Dent. 1999;11:311-24.

36. Lombardi RE. The principles of visual perception and their clinical application to denture esthetics. J Prosthet Dent. 1973:29(4):358-82.

37. Magne $\mathrm{P}$, Belser $\mathrm{U}$. Bonded porcelain restorations in the anterior dentition: a biomimetic approach. Chicago: Quintessence; 2001.

38. Masioli M. Fotografia odontológica. 2a ed. Porto Alegre: Artmed; 2010

39. Mattos C, Santana RA. Quantitative evaluation of the spacial displacement of the gingival zenith in the maxillary anterior dentition. J Periodont. 2008;79(10):1880-5

40. Mayekar SM. Shades of color: illusion or reality? Dent Clin North Am. 2001:45(1):155-72

41. Morley J, Eubank J. Macro esthetic elements of smile design. J Am Dent Assoc. 2001;132(1):39-45.

42. Mucha JN. As limitações do tratamento ortodôntico não-cirúrgico. In: Medeiros PJ, Medeiros PP. Cirurgia ortognática para ortodontista São Paulo: Ed. Santos; 2004. p. 29-56.

43. Müller HP, Eger T. Masticatory mucosa and periodontal phenotype: a review. Int J Periodontics Restorative Dent. 2002;22(2):172-83.
44. Naini FB, Moss JP, Gill DS. The enigma of facial beauty: esthetics, proportions, deformity, and controversy. Am J Orthod Dentofacial Orthop. 2006;130(3):277-82.

45. Orce-Romero A, Iglesias-Linares A, Cantillo-Galindo M, Yañez-Vico RM, Mendoza-Mendoza A, Solano-Reina E. Do the smiles of the world's most influential individuals have common parameters? J Oral Rehabil. 2013:40(3):159-70

46. Rotundo R, Nieri M, lachetti G, Mervelt J, Cairo F, Baccetti T, Franchi L, Prato GP. Orthodontic treatment of periodontal defects. A systematic review. Prog Orthod. 2010;11(1):41-4.

47. Sarver DM, Ackerman MB. Dynamic smile visualization and quantification Part 2. Smile analysis and treatment strategies. Am J Orthod Dentofacial Orthop. 2003:124(2):116-27.

48. Sarver DM, Ackerman MB. Dynamic smile visualization and quantification and its impact on orthodontic diagnosis and treatment planning. In: The art of smile: integrating Prosthodontics, Orthodontics, Periodontics, Dental Technology and Plastic Surgery. Chicago: Quintessence; 2005. p. 99-139.

49. Sarver DM. The importance of incisor positioning in the esthetic smile: the smile arc. Am J Orthod Dentofacial Orthop. 2001;120(2):98-111.

50. Sarver DM. Principles of cosmetic dentistry in orthodontics: Part 1. Shape and proportionality of anterior teeth. Am J Orthod Dentofacial Orthop. 2004;126(6):749-53.

51. Sarver DM. Soft-tissue-based diagnosis and treatment planning Clin Impress. 2005:14(1):21-6.

52. Sarver DM. Enameloplasty and esthetic finishing in orthodontics: identification and treatment of microesthetic features in Orthodontics. Part 1. J Esthet Restor Dent. 2011;23(5):296-302.

53. Sarver DM. Enameloplasty and esthetic finishing in orthodontics: differential diagnosis of incisor proclination - the importance of appropriate visualization and records Part 2. J Esthet Restor Dent. 2011:23(5):303-13.

54. Schillinburg HT, Kaplan MJ, Grace CS. Tooth dimensions. A comparative study. J South Calif Dent Assoc. 1972;40(9):830-9.

55. Schillinburg HT. Fundamentals of fixed prosthodontics. 3a ed. Chicago: Quintessence; 1997.

56. Shellhart WC, Lange DW, Kluemper GT, Hicks, EP, Kaplan AL. Reliability of the Bolton tooth-size analysis when applied to crowded dentitions. Angle Orthod. 1995:65(5):327-34

57. Spear FM, Kokich, VG. A multidisciplinary approach to esthetic dentistry Dent Clin North Am. 2007:51(2):487-505.

58. Sterrett JD, Oliver T, Robinson F, Fortson W, Knaak B, Russell CM. Width/ length ratios of normal clinical crowns of the maxillary anterior dentition in man. J Clin Periodontol. 1999:26(3):153-57.

59. Tarnow DP, Magner AW, Fletcher P. The effect of distance from the contact point to the crest bone of the presence or absence of the interproximal dental papilla. J Periodontol. 1992;68:995-6.

60. Thilander B. Orthodontic space closure versus implant placement in subjects with missing teeth. J Oral Rehabil. 2008;35 Suppl 1:64-71.

61. Zachrisson BU. Orthodontics and periodontics. In: Lindhe J, Karring T, Lang NP. Clinical Periodontology and Implant Dentistry. 3rd ed. Copenhagen: Blackwell Munksgaard; 1997. p. 741-93.

62. Zachrisson BU. Esthetic factors involved in anterior tooth display and the smile: vertical dimension. J Clin Orthod. 1998;32(7):432-45.

63. Zanetti GR, Brandão RCB, Zanetti LSS, Castro GC, Borges Filho FF. Integração orto-perio-prótese para correção de assimetria gengival: relato de caso. Rev Dental Press Estét. 2008:5(4):104-15 